\title{
Multicriteria Evaluation of Transport Plan for High-Speed Rail: An Application to Beijing-Xiongan
}

\author{
Asim Farooq $\mathbb{D}^{1},{ }^{1}$ Mowen Xie $\mathbb{D}^{1},{ }^{1}$ Svetla Stoilova, ${ }^{2}$ and Firoz Ahmad $\mathbb{D}^{3}$ \\ ${ }^{1}$ School of Civil and Resource Engineering, University of Science and Technology, Beijing, China \\ ${ }^{2}$ Transportation Department, Technical University of Sofia, Bulgaria \\ ${ }^{3}$ Vindhyan Ecology and Natural History Foundation, Mirzapur, Uttar Pradesh, India \\ Correspondence should be addressed to Asim Farooq; asimfarooq1234@gmail.com and Mowen Xie; mowenxie@ustb.edu.cn
}

Received 12 March 2019; Revised 4 April 2019; Accepted 8 April 2019; Published 12 May 2019

Guest Editor: Danielle Morais

Copyright (C) 2019 Asim Farooq et al. This is an open access article distributed under the Creative Commons Attribution License, which permits unrestricted use, distribution, and reproduction in any medium, provided the original work is properly cited.

\begin{abstract}
Beijing has an enormous transportation challenge: to relieve the extreme congestion that has arisen, largely due to overpopulation. To meet this challenge, the city administration has decided to extend its territory; a new city will be planned and built. This new city, Xiongan, will reduce the burden on the capital. A new high-speed railway (HSR) line is designed to transport millions of people every day within less than an hour. This study applies the potential of Geographical Information Systems (GIS) and multicriteria methods, Analytic Hierarchy Process (AHP) and Preference Ranking Organization Method for Enrichment Evaluations (PROMETHEE II), to determine the best alternative of transportation for the new high-speed railway line between Beijing and Xiongan, comparing different ones. The methodology consists of two stages. In the first stage remote sensing datasets such as ASTER DEM and LANDSAT images and GIS software such as ERDAS IMAGINE and ArcGIS have been used to determine settlement distribution, station location, elevation model, slope percentage, vegetation percentage, and route alignment for a new high-speed railway line for better understanding of its spatial distribution pattern over the study area. The second phase of the study focusing on assessing the various alternatives of transportation has been determined, and three approaches to choosing the best alternative have been introduced. In the paper we examine criteria associated with travel and economic criteria: travel time, the number of train stops, public satisfaction with transport, the number of seats per day, connectivity, operating costs, profit, and the payback period. Six alternatives of transportation have been studied. The stops in Guan and stations in the metro's rings have been investigated. In the second stage, the Analytic Hierarchy Process (AHP) and PROMETHEE II methods have been used to select the best alternative. The first approach uses only criteria related to the trip, as the criterion to choose the best alternative is the maximum of the net outranking flows by PROMETHEE II method; the second approach applies two independent criteria: the ratio of normalized operating costs and the normalized net outranking flows, and the ratio of the normalized payback period and the normalized net outranking flows; the third approach includes all defined criteria, and the criterion of choosing the best alternative is the maximum of net outranking flows as calculated by the PROMETHEE II method. The approaches have been analyzed with the purpose of comparing the results. The result indicates that it is expedient to have a station in Guan, which will increase the connection and connectivity among the cities while providing fast mobility options for a large number of inhabitants of Guan city. Furthermore, the result from Remote Sensing and GIS analysis demonstrates that the proposed high-speed railway line will be environmentally sustainable and is economically/socially feasible and that it will certainly attract current and future passengers because of their needs.
\end{abstract}

\section{Introduction}

The population of Beijing has increased rapidly, and further migration towards the capital city is increasing at an exponential rate. Due to urbanization, the city is facing challenges such as traffic congestion, rising real estate prices, environmental pollution, overpopulation, and dependency on private vehicles [1]. It feels impelled to address the instability generated by uncontrolled growth and to start planning to deal with the problems caused by the consequent overspill. Many studies characterize the current state of Beijing by words such as "urban disease" and "urban ill" 
$[2,3]$. Urbanization in China is booming on an unprecedented scale, improving people's lives but also creating massive challenges for the country and people [4]. Development generated by urbanization in China is at its height; most of the new job opportunities occur in new urban areas [5]. The capital city stretches for $100 \mathrm{~km}$ wide; it has 18 subway lines and 13 more under construction and has 6 ring roads built around Tiananmen Square in piecemeal fashion following a pattern of concentric circles centered on Tiananmen Square [6]. The populations of Beijing, Tianjin, and Hebei are 22 million, 15.5 million, and 74.3 million, respectively, and their annual growth rates have reached $16.2 \%, 14.4 \%$, and $11.6 \%$, respectively [7]. Therefore, there is a huge gap in the development of these three areas; Hebei needs to sustain almost four times the population of Tianjin and Beijing.

Beijing decided to extend its municipal administration to Hebei province on the border with Tongzhou to reduce the population burden on the capital [6]. The newly built area "Xiongan" will act as an auxiliary capital, providing population relief to the massive capital city [3]. In the initial phase, the administration decided to plan for 2 to 2.5 million people [8]. For Beijing, it is necessary to solve the problem of choosing a transport connection with the newly formed satellite city of Xiongan. The current project is located in Hebei; it is hoped thereby that it will close the developmental gap by providing job opportunities and a boost to the local economy. Xiongan is planned to be built between the present counties of Xiong, Rongcheng, and Anxin, from which it obtains the name "XiongAn". The newly developed area, also called "Jing-Jin-Ji", will connect Beijing, Tianjin, and Hebei and is designed to increase economic activity and close the gap in development between these three provinces. The key characteristic of the capital city is its strategic position as the center of politics, along with international exchange, culture, and technology and innovation; the noncapital functions will move to the newly built area [3]. The newly selected location is ideal for such a mega plan; as documented by the same white paper, the area is low in population density, has a low level of development and thus ample space for further development, and is highly suited to construction [9].

In the early 20th century, sixteen cities throughout the world surpassed a million in population [10]; after 1950 this rate increased until it reached 411 in 2010 [11]. Migration from rural to urban areas and population growth have increased all over the world. In 2050, 70\% of the world population is expected to live in cities, which will cause a threefold increase in urban journeys [12]. Rapid expansion of motorization causes many problems such as congestion, noise, emissions, and safety risk and so carries an economic and social cost [13]. Naturally therefore smart mobility became a topic of huge interest for researchers, who competed in suggesting different measures to achieve smart sustainable cities [10, 14, 15]. Proposed transportation networks need to satisfy a variety of criteria: demand, technical feasibility, detailed quantitative evaluation, clear objectives and constraints, travel time, cost of travel, safety, reliability, accessibility, and the environment [16].

Transportation planning is complex to achieve at the design and planning level. The rapid expansion of cites also tends to cause transportation networks to be spread around large areas, within which the long-distance regional rail network is formed [17]. Travel mode selection is based on high reliability, shorter travel time, higher operational efficiency, and the need for fewer transfers [18]. Cities are expanding rapidly, and noncapital functions tend to move to the suburbs, thereby causing an increase in the numbers of passengers [18]. Many studies have been done for the railway which consider different parameters as per the study outcome, such as [19] shortest travel time and passenger satisfaction [20, 21]. Timetable studies seek to reduce passenger waiting time [22] and passenger transfer [23] and to minimize travel time, energy consumption [24], and precipitation time [25]. Recent studies mainly focus on the level of service level, selecting the shortest route possible, and traffic capacity [26]. Sustainable mobility is a smart tool to reduce congestion, pollutants caused by traffic, and emissions and to improve the quality of the environment $[10,14]$. During the Reform and Opening Up, migration increased from rural to urban areas due to many factors, such as higher quality of life and employment opportunities [27], and in search of affordable homes a major percentage of people also moved to nearby areas (Urban Sprawl) [28]. From 1980 till 2010, Chinese migration was only analyzed from rural to urban areas and from west to east [29]. More recently, after the implementation of the high-speed railway (HSR) network, migration is observed from the east to urban areas, now that people work in one city and live in another [30].

The smart sustainable model for transport should reduce the demand for transport and dependency on the car, while designing urban space in such a way that it can be attractive and easily accessible by public transport $[31,32]$. Each urban and transport model objective should increase connection and connectivity, urban quality of life, and transit-oriented development (TOD); be multimodal, effective, safe, and reliable; and have less adverse effect on the environment [33]. To change individual or overall transport travel behavior is a long-term complex process [10]. Sustainable urban mobility is likewise a long-term process, the achievement of which can be possible through strategies, initiatives, parameters, goals, and targets; increase the passenger attraction connected with modern mobility; and improve the technological innovation to increase effectiveness of overall system [14, 34]. Transportation bottlenecks are the major impediment to economic growth in Chinese megacities; to vitalize economic options, time-space shrinkages, and sustainable mobility options, HSR is the best solution for the country $[35,36]$.

HSR is considered a modern 20th century transportation tool [37]; many developed countries in the world have adopted HSR and are still investing in it $[38,39]$. Attitudes to HSR in China are quite favorable, and the government is investing huge capital each year to build and extend the length of HSR lines [40]. High-speed railway was launched in early 2008 between Beijing and Tianjin; in 2009 another line came into service between Guangzhou and Wuhan [41]. In 2015, China became a world leader in HSR, with a total of $19,000 \mathrm{~km}$ [42]. HSR is a hot topic for many researchers in China. Under consideration are issues such as social issues, railway scheduling, operational management [43], 
efficient stop optimization [23, 43], safety [44, 45], passenger flow, HSR passengers behavior [46], increasing connection and connectivity [16], circuity analysis [47], and capacity optimization [48]. HSR network has quite positive impacts on people's lives, travel behavior, and household mobility; promotes and encourages tourism and travel activities; and strengthens social interactions and employment opportunities [49-53].

China is growing at a rapid pace; many areas have converted to high-rise buildings which have reduced the appeal of living in cities for many average-income people [54]. Previous studies provide evidence that HSR increases the option of living in better and more affordable cities as per individual choice, where people live in one city and work in another. Chinese cities where this has been shown to be the case include Guangzhou-Foshan, ShanghaiSuzhou, Shenzhen-Huizhou, and Beijing-Tianjin [55, 56]. HSR changes the migration patterns in China. For example, between Beijing and Tianjin, people work in Beijing but live in Tianjin because of the affordability of housing in Tianjin as compared to Beijing [54]. HSR has improved Chinese economic development, travel convenience, and opportunities for job creation as observed by local people [57]. It has also secured improvement in regional economies [58] and in local social structure and life $[59,60]$.

Geographic Information Systems (GIS) and multicriteria analysis (MCA) are methods that can be used to study and analyze transport systems. GIS works as a modeler object, while MCA works as a decision object. By combining them, the optimum result for any project can be achieved [61]. In the present research GIS is used for searching the optimal route, short route analysis, and optimal path analysis, while AHP and PROMETHEE are used to determine the weights of criteria [62]. The combination of GIS and AHP is a strong planning tool; GIS helps to analyze different factors, while AHP is used to assign weight to these factors on the basis of their relative importance, which can be of great help to decision makers and planners [63]. The combination of GIS and AHP is widely used to achieve sustainability in transportation by measuring territorial impact, transport alternatives, accessibility improvements, environmental impacts, and landscape connectivity [64] to focus on alternatives and potential indicators needed for planning the high-speed railway line. Another study was carried out through GIS and AHP for land use allocation, land use planning, and land use proposal deliberation [65]. The combination of PROMETHEE and AHP is used by many studies on transportation to determine mode selection, route selection $[66,67]$, average waiting time, and operational efficiency [68]. The combination of AHP and PROMETHEE has been used in past studies to determine route selection and mode of transportation and to evaluate different transportation related issues. The criterion for selecting the optimal transport alternative is introduced-the minimal value of the ratio between normalized operating costs and normalized PROMETHHE scores. Combinations of GIS, AHP, and PROMETHEE have been used to determine the mode of transportation, to evaluate transport projects, and to select route $[67,69]$. To choose the optimal transport type with regard to safety, access, cost, capacity, speed, and reliability, AHP and PROMETHEE are applied in [67]. In addition [70], transport planning was determined with the help of the multistakeholder, multiobjective, and AHP modeling to calculate minimum costs. The combination of PROMETHEE, AHP, and GIS has been applied for susceptibility landslide mapping [71], improvement of healthcare waste management, centralized location selection for modern waste [72], and the evaluation and selection of ecotourism sites [73]. PROMETHEE and AHP are used to select transportation infrastructure [74] and select the optimal alternative for an intercity train [68]. In [75], AHP and the Multidimensional Cost Model are used to find the optimal road transport path for the purpose of reducing the traffic congestion. In [76] AHP and GIS are applied to determine the accessibility patterns of new housing development, to make cost-benefit analyses with regard to residents' access to facilities.

It may be concluded that the application of the GIS and multicriteria methods such as AHP and PROMETHEE can serve as a basis for creating a model for passenger transportation for the new railway line. The number of stations on the line depends on many factors, such as travel time, number of passengers, frequency of services, and investment. When selecting the best transport alternative, it is necessary to compare different alternatives and choose the best one by given criteria.

It can be summarized that the multicriteria methods are an appropriate tool to make decision and analyze complex problems due to their ability to assess different alternatives on various criteria for possible selection of the suitable alternative. When developing transport technology, it is necessary to take into account both the possibilities of the transport operators and the requirements of the passengers; i.e., it is necessary to assess different criteria. The main methodological steps for the selection of the suitable alternative from set of available alternatives by using multicriteria methods can be summarized as follows: defining the criteria, establishment of alternatives, appropriate data collection, selection of method to solve the problem, choosing the suitable alternatives.

The aim of the present study is to determine the best transportation alternative between compared ones for a new high-speed railway line between Beijing and Xiongan using GIS and multicriteria analysis. The combination of both methods permits assessment of many quantitative and qualitative indicators, at the same time also taking into account the design of the railway line. The paper is organized as follows. In Section 2 we present the research methodology in two stages: the first is the application of ArcGIS and ERDAS IMAGINE to determine the high railway line, and the second is a combination of AHP (shown in Appendix A) and PROMETHEE II (shown in Appendix B) method for choosing the best alternative of transportation. In Section 3, by applying our proposed approach to the Beijing to Xiongan high-speed railway line, the study demonstrates the effectiveness of this methodology by numerical results. Conclusions are given in Section 4. For reference, the appendix provides the basics of the AHP and PROMETHHE II methods. 


\section{Methodology}

The methodology is based on application of GIS and multicriteria methods AHP and PROMETHEE II. The remote sensing of GIS software was used for better understanding and knowledge of its spatial distribution pattern over the study area. The model does not generate input data for the multicriteria model. The AHP method is applied to determine the weights of criteria, and PROMETHEE II technique is used for ranking the alternatives. The methodology includes three approaches to decision making: the first approach is based only on criteria connected to the trip into PROMETHEE II model; the second approach uses complex criteria for ranking; the third approach is based on all defined criteria which are applied to PROMETHEE II model. These approaches serve as a sensitivity analysis of results.

The methodology comprises two stages.

2.1. Stage 1. Stage 1 includes identifying the suitable locations for stations, elevation mode, slope percentage, and the proposal of a new railway line between cities by using ArcGIS and ERDAS IMAGINE. In this analysis, we have utilized highend satellite datasets such as Landsat- 8 and the Advanced Spaceborne Thermal Emission and Reflection Radiometer (ASTER) Digital Elevation Model (DEM). In the first step, they were mosaicked to adequately represent the study area. The ERDAS IMAGINE high-end image processing software [77] and ArcGIS: rigorous GIS analysis software [78] were utilized to create classified output such as land use categories of settlement and vegetation. The ArcGIS software was used to create a systematic grid over the specified buffer area. Various themes such as settlement percentage (\%), slope \%, elevation, and vegetation $\%$ were calculated and produced in the form of various maps to understand the feasibility of new routes, using population data, road network, railway network, and recreational data. Such a GIS investigation systematically reveals that a new proposed line is significantly suitable relative to the environment/cost/socioeconomic aspect of the human settlement of the region. Furthermore, it will adequately help the present and future population and support their needs in a sustainable manner. Additionally, the various themes/layers produced here were not used as an input data for the multicriteria model.

2.2. Stage 2. Stage 2 includes defining alternatives of the organization of trains on the new railway line, defining criteria for selecting the best alternative, ranking the alternatives, and choosing the best one.

Stage 2 includes the following steps.

Step 1. Determining the alternatives: these alternatives for the transport plan of passenger trains are formed according to the number of stops at the stations.

Step 2. Determining the criteria of the alternatives assessment: in the study the following criteria are introduced:

(i) C1: travel time (min) (this is an important factor for attracting passengers).

(ii) C2: number of train stops (this is also a factor relevant to passenger satisfaction). (iii) C3: transport satisfaction, trains/day (this represents the frequency of transport services).

(iv) C4: number of seats /day (this is important for attracting passengers for trips).

(v) C5: connectivity (this is important for the convenience of traveling and the total journey time from the starting point to the final destination). The values of this criterion are set by 0 or 1 . $C 5=1$ if the alternative has connection with metro, and $\mathrm{C} 5=0$ otherwise.

(vi) C6: operating costs, millions of US dollars (this factor is important for the carrier).

(vii) C7: profit, millions of US dollars/year (this factor is important for the carrier).

(viii) C8: payback period, years (this specifies the return on the investment).

These criteria are important to assess the transportation and the economic impact on alternatives. The criteria are defined by authors taking into account different conditions of transportation, due to the different numbers of stops in the route, and the need for investment for expansion or new construction of stations.

Within the study three approaches have been applied to determine the best alternative.

(1) First Approach. The optimal alternative is defined according to the impact of criteria connected to the trips (C1-C5). The weight given to each of the criteria is determined by AHP. These weights are fed into PROMETHEE to determine the best alternative by criterion maximum of net outranking flows.

$$
\varphi_{f}^{(1)} \longrightarrow \max
$$

The research uses PROMETHEE II outranking method which is based on a preference function approach [79]. It is one among the 6 variations of PROMETHEE. PROMETHEE I is used for partial ranking of the alternatives, PROMETHEE II is for complete ranking, PROMETHEE III is applied for ranking based on interval, PROMETHEE IV is for complete or partial ranking of the alternatives with a continuous set of solutions, PROMETHEE V is for problems with segmentation constraints, and PROMETHEE VI provides the decision maker with additional information on his own personal view of his multicriteria problem. PROMETHEE methods have a simple mathematical approach and are user-friendly. The PROMETHEE II method is based on the pairwise comparison of alternatives along each defined criterion. It requires two additional types of information: weights of the criteria and a decision maker's preference functions, which were used for comparing the alternatives. PROMETHEE II is the most frequently applied version because it enables one to find a full-ranking of alternatives.

(2) Second Approach. The best alternative is chosen by taking into account both the impact of the costs presented by criteria C6-C8 and the complex effect of the benefits presented by criteria $\mathrm{C} 1-\mathrm{C} 5$. The criteria $\mathrm{C} 6-\mathrm{C} 8$ are not introduced into the 
PROMETHEE model. The impact is examined separately; the optimization is made by using a complex criterion.

In this study we have been using the following complex optimization criteria, which have been applied separately for all the alternatives investigated:

(a) Minimum value of ratio $r_{f 1}$ of the normalized operating costs and the normalized scores corresponding to the PROMETHEE II priority [68]:

$$
r_{f 1}=\frac{c_{f}}{a_{f}} \longrightarrow \min
$$

where $c_{f}$ are the normalized values of operating costs; $a_{f}$ is the normalized net outranking flow by PROMETHEE II method for alternative $f ; f=1, \ldots, F$ is the number of alternatives.

The normalized values of operating costs are

$$
c_{f}=\frac{R_{f}}{\sum_{f=1}^{F} R_{f}}
$$

where $R_{f}$ is the operating costs for alternative $f$, USD/year. These costs include the costs for movement of the trains (electricity), for stop-braking and accelerating of the trains, for maintenance and repair of the rolling stock, for salaries for all personnel, for personnel at the stations on the route, and for infrastructure charges.

The normalized values of net outranking flow by PROMETHEE II are determined according to [68]:

$$
a_{f}=\frac{\varphi_{f}^{(1)}+M}{\sum_{f=1}^{F}\left(\varphi_{f}^{(1)}+M\right)}
$$

where $M$ is a positive integer that should make all net outranking flow $\varphi_{f}^{(1)}$ positive; $\varphi_{f}^{(1)} \in[-1 ; 1]$ is net outranking flow by PROMETHEE II for alternative $f$.

This criterion takes into account both criteria presented by the impact of the trips and economic criteria.

(b) Minimum value of ratio $r_{f 2}$ of the normalized values of the payback period and the normalized scores corresponding to the PROMETHEE II priority.

In the study the building of the new railway line and stations is investigated. Therefore, it is important to include in the optimization criterion the factors that are relevant to the amount of investments, costs, and revenues.

The payback period is one of the simplest investment appraisal techniques. It presents the time at which the initial cash outflow of an investment is expected to be recovered from the cash inflows generated by the investment. The payback period is determined as follows:

$$
P_{f}=\frac{I_{f}}{W_{f}-R_{f}}, \text { years }
$$

where $W_{f}$ is the revenue of the trips, million USD/year; $I_{f}$ are the investment costs, million USD. follows.

The normalized values of the payback period are as

$$
p_{f}=\frac{P_{f}}{\sum_{f=1}^{F} P_{f}}
$$

The criterion of choosing the best alternative is the minimum value of ratio $r_{f 2}$ of the normalized values of the payback period, and the normalized scores corresponding to the PROMETHEE II priority are determined as follows:

$$
r_{f 2}=\frac{p_{f}}{a_{f}} \longrightarrow \min
$$
$P_{f}$

where $p_{f}$ are the normalized values of the payback period

(3) Third Approach. The best alternative is defined according to the impact of all criteria (C1-C8). The weights of the criteria have been determined by AHP. These weights are fed into PROMETHEE II to determine the best alternative by criterion maximum of net outranking flows.

$$
\varphi_{f}^{(2)} \longrightarrow \max
$$

The value of net outranking flows means PROMETHEE II score.

(4) Choosing the Best Alternative. All three approaches are considered when making the final decision. They are accepted as a tool for sensitivity analysis for suitable alternative.

The alternatives are ranked based on each of the criteria defined by formulas (1), (2), (7), and (8). The ranking of the alternative given by each of the criteria corresponds to the scores under this alternative.

\section{Results and Discussion}

The numerical experiments of high-speed railway line between Beijing and Xiongan have been conducted to evaluate the proposed methodology.

3.1. First Stage. In the first stage of the study, ArcGIS was used to analyze the two city spatial distribution patterns in detail. In stage 2, the stop for HSR can be located in Beijing and how many stops are really needed was determined. Through ArcGIS, the location for the station was selected on the basis of the availability of land next to the station, the possibility of future extension, the price of land, and subway connections. Furthermore, during the analysis the elevation model, settlement percentage, slope percentage, and vegetation model were determined for the proposed route, extending from Beijing to Guan and then Xiongan. On the basis of an analysis of the average circular distances between each ring road in Beijing, a buffer of $30 \mathrm{~km}$ was sketched in order to analyze possible passenger demand and attraction. The stations were considered on the basis of population buffer, such as $30 \mathrm{~km}$ in Beijing, but $5 \mathrm{~km}$ at Guan and $30 \mathrm{~km}$ at Xiongan. The distance between each of the six ring roads in Beijing varies: the average distance between the second and third ring road is $2.4 \mathrm{~km}$, between the $3 \mathrm{rd}$ and the $4 \mathrm{th}$ $2.7 \mathrm{~km}$, between the 4 th and the 5 th $4 \mathrm{~km}$, and between the 5 th and the 6 th approximately $11 \mathrm{~km}$. The city was designed accordingly, with development being based on ring road allocation. The 6 th ring road is considered to be at the border of the city and has relatively less population. The distance 


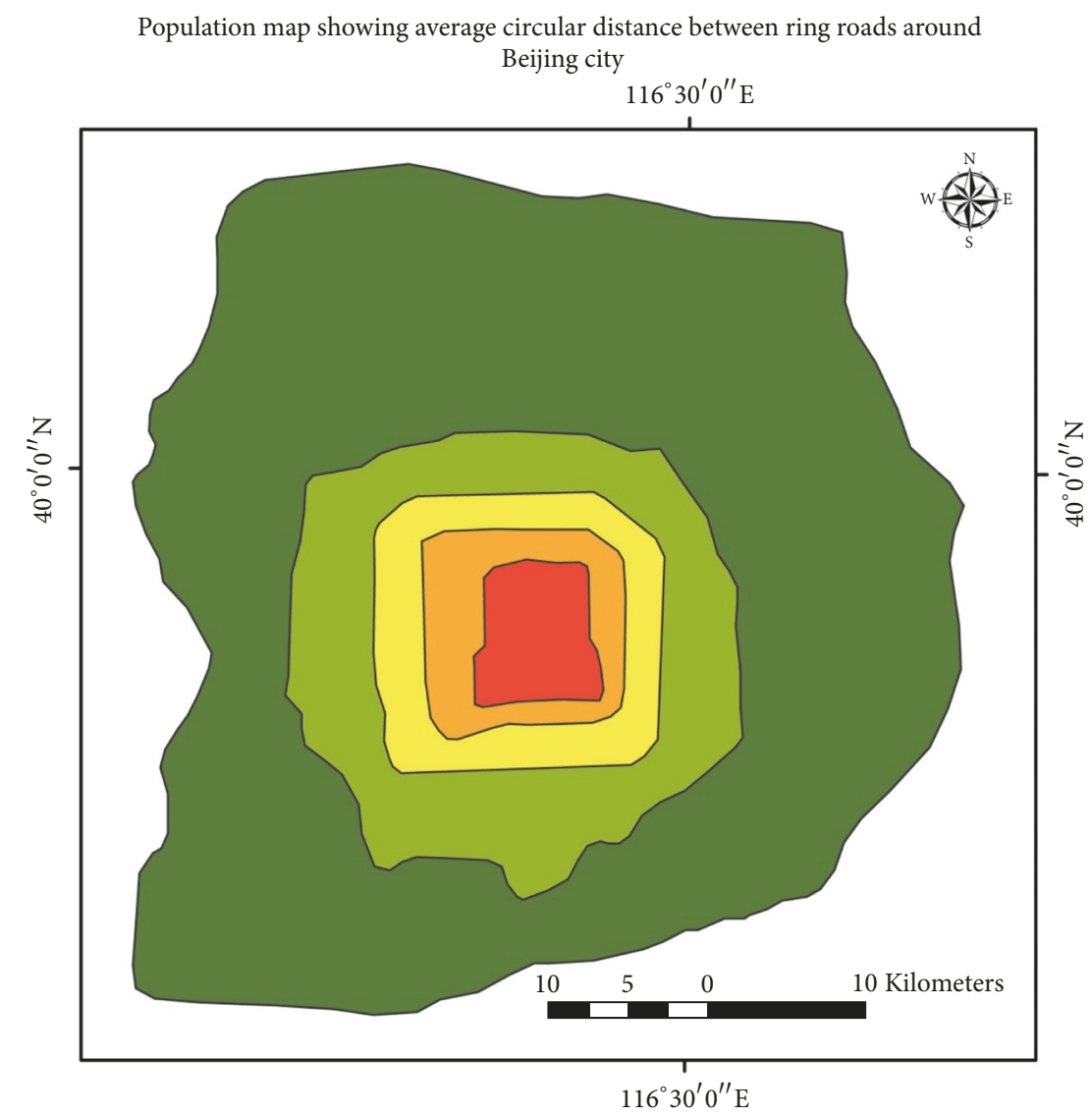

Population Density ( People/Sq. Kilometer)

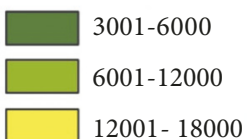

Average circular distance between ring roads 2 nd to $3 \mathrm{rd}$ ring road: $2.4 \mathrm{Km}$ $3 \mathrm{rd}$ to 4 th: $2.7 \mathrm{Km}$ 4 th to 5 th: $4 \mathrm{Km}$ 5th to 6th: $10.7 \mathrm{Km}$

FIGURE 1: Beijing population index along with circular distance between each ring road.

from the 6th ring road to Xiongan is $80 \mathrm{~km}$, and from the 6th ring road to the center of Beijing $125 \mathrm{~km}$. In the middle there is a tiny town called Guan, which is $30 \mathrm{~km}$ from the 6 th ring road and $51 \mathrm{~km}$ from Xiongan. The purpose of Figure 1 is to clearly indicate the overall idea about distances of each ring road from the center and the population density between each ring road. Figure 2 shows the overall settlement image along with population buffer (passenger attraction area) from Beijing to Guan to Xiongan. The HSR buffer of $5 \mathrm{~km}$ is used in the figure for route allocation, while along Beijing and Xiongan $30 \mathrm{~km}$ passenger buffer is used.

The total traveling time (as analyzed by Baidu software) from Beijing to Baoding, the area near to that of the study, is around three and a half hours using the local intercity railway line. The current proposed line will follow the last station on the 6th ring road, follow the route which stops and Guan, and then proceed to the destination. The line as currently proposed will deliver passengers there in less than one hour.

The circle is the center of Guan city which shows that the spatial structure of settlement depicted in the form of percent is significantly high near the center. The study from
GIS analysis verifies that the population settlement is quite dominated in this area which retains approximately 520,000 inhabitants; there are industries and educational institutions, with huge population density (as shown in Figure 2). The study suggests that if the new line passes through the area near Guan, which will serve a large number of inhabitants, it will increase the passenger attraction between Beijing and Xiongan.

The elevation map is designed around the proposed highspeed railway line, with Xiongan at low and Beijing at high elevation. The variation in elevation between the two is quite gradual and will significantly facilitate the construction of transportation infrastructure which will be a sustainable option for connecting the capital to Xiongan (as shown in Figure 3).

As shown in Figure 4, the settlement is near the proposed buffer line; furthermore the line also takes into account future growth of passenger traffic, specifically in the new stations at Guan and Xiongan. The line will facilitate the day to day activities of huge numbers of people and secure the supply of food to newly built city. The general slope 


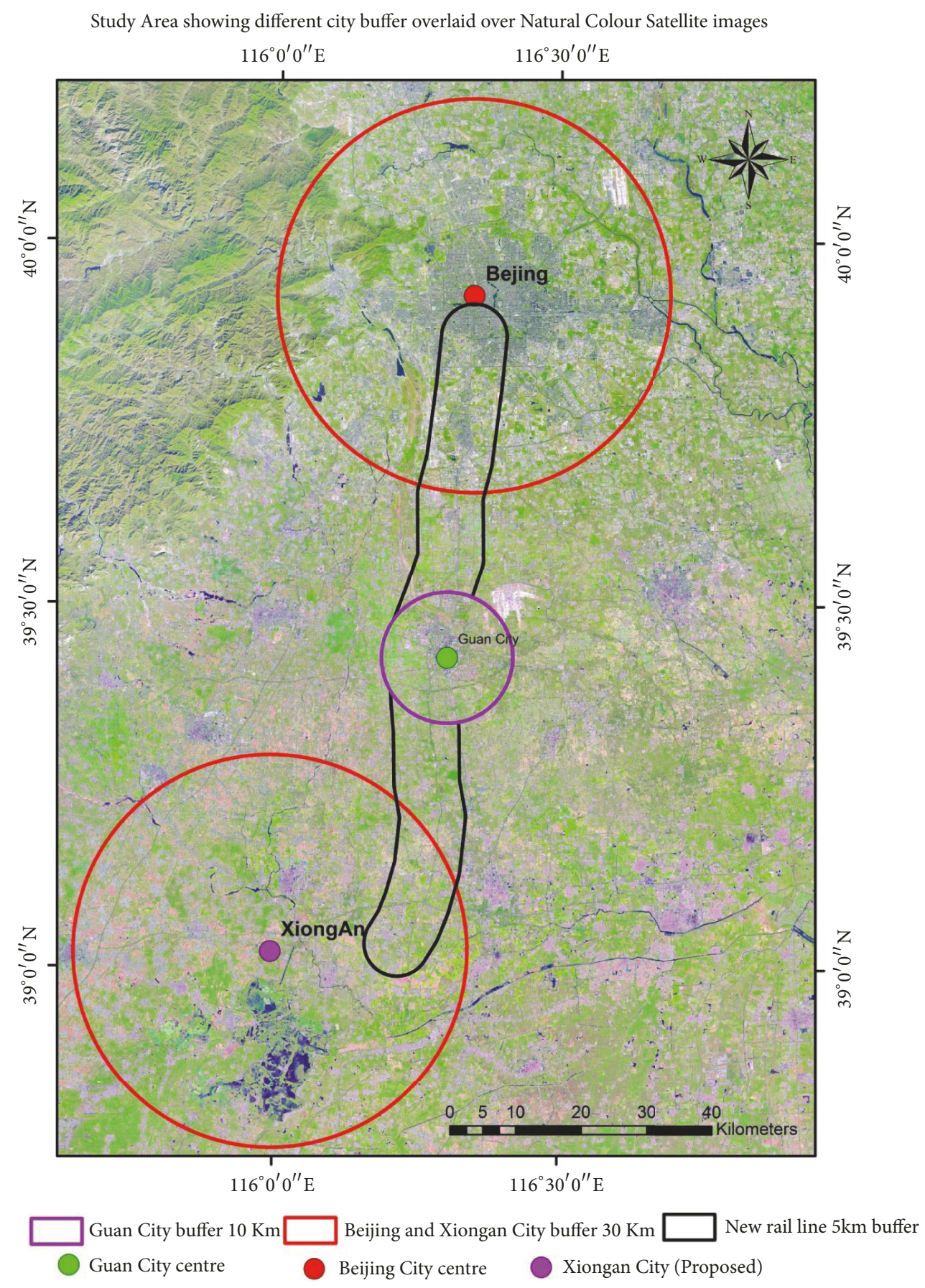

FIGURE 2: HSR proposed route alignment between Beijing and Xiongan.

percent (Figure 7) trend is moderate to low and therefore economically sustainable (a high slope percent requires more cutting operations) and will support the construction of transportation infrastructure such as rail lines, bridges, and tunnels as shown in Figure 5. The vegetation in study area, as shown in Figure 6, comprises mainly agricultural fields, vineyards, orchards, and pastureland. The spatial distribution pattern of vegetation percent also indicates that the construction of the new rail line will have little adverse effect on natural vegetation. The protection of nature through the protection of biological and landscape diversity is a key issue relative to rendering the project environmentally feasible, as indicated by Figure 5 .

3.2. Second Stage. In this paper we examine the intermediate stops in three Beijing stations located in the metro rings and one in Guan. The stops in the metro rings would increase the connectivity and convenience of the trip. The study plans the extension of these stations so as to be able to serve high-speed trains. Guan is situated between Beijing and Xiongan. The 


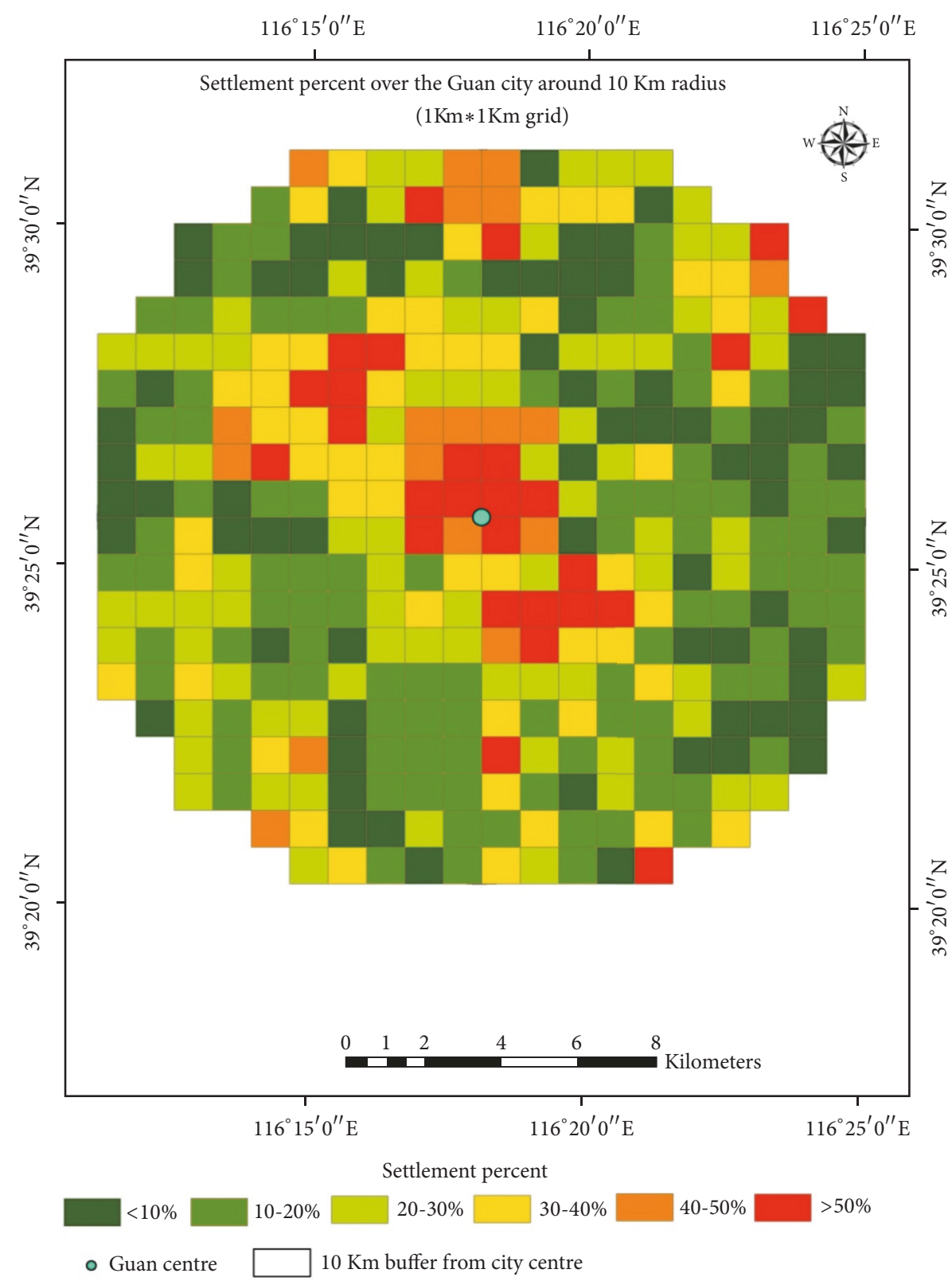

FIGURE 3: The density of settlement at Guan $(1 \mathrm{~km} * 1 \mathrm{~km}$ grid spacing) from Landsat-8 satellite image at $10 \mathrm{~km}$ radius of Guan city.

population of Guan is 516,735 habitants. The construction of the station in Guan would contribute to the expansion of this satellite city while reducing the population of Beijing.

Six different alternatives of transportation have been formed taking into account proposed stations between Beijing and Xiongan. Figure 8 presents these alternatives. They differ in the number of stops and stations for stopping. The alternatives are as follows:

(i) Alternative 1: There are stops in three intermediate stations in Beijing.

(ii) Alternative 2: There are stops in three intermediate stations in Beijing and one in Guan.

(iii) Alternative 3: This alternative provides a direct service with no stops. (iv) Alternative 4: This service includes one stop in Guan.

(v) Alternative 5: The intermediate stops are at the most distant station in the metro ring (Huangcun railway station) and also in Guan.

(vi) Alternative 6: This service includes one stop in the most distant station in the metro ring.

The location of Guan railway station and also the distances and travel time between railway stations have been determined by using ArcGIS. The track of the railway line is made by using ArcGIS.

Calculations are based on the following conditions:

(i) The high-speed trains are composed of 8 wagons and carry 600 passengers in one direction. 


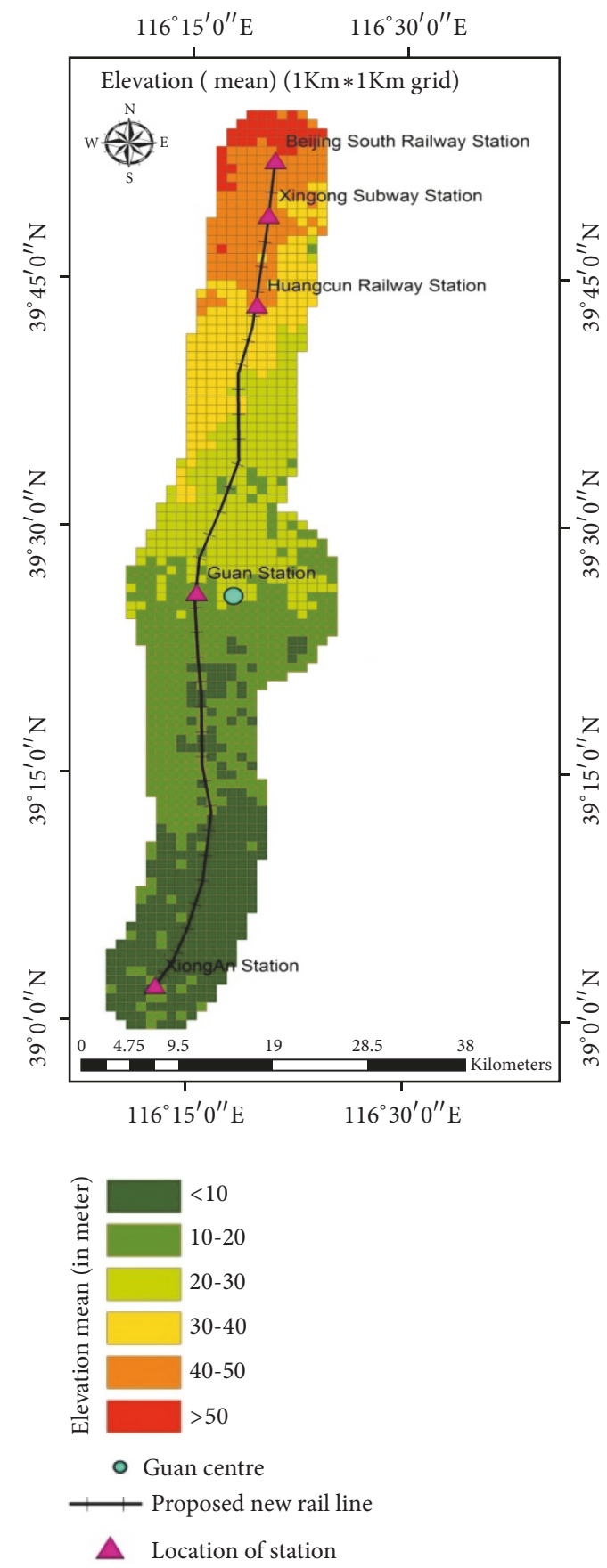

FIGURE 4: The mean elevation ( $1 \mathrm{~km} * 1 \mathrm{~km}$ grid spacing) from ASTER Digital Elevation Model (DEM).

(ii) The investment costs for the new station building are taken to be 1900 million USD. Similar investment was made for stations in new high-speed railway lines elsewhere in China. According to the size of the station, the cost of stations varies, with small stations (3,000 sq. $\mathrm{m}$ station building) costing about RMB 40 million (5.7 million USD) to RMB 13 billion (1900 million USD) [80, 81].

(iii) The investment costs for the extension of stations have been accepted by experts. The value is $5 \%$ of the value of a new railway station building. (iv) The costs for electricity to power the trains are 13 USD $/ \mathrm{km}$ according to Chinese Railways. This data is similar to that for the Beijing to Guangzhou highspeed railway line for Engine Type CRH380A for a train with eight wagons [82]

(v) The costs for braking and accelerating in intermediate stops are determined as $0.2 \%$ of costs of movement. This value was accepted according to [83] which documents the research of high-speed train energy consumption. Furthermore, regenerated energy from the trains is assumed to be consumed by other trains 


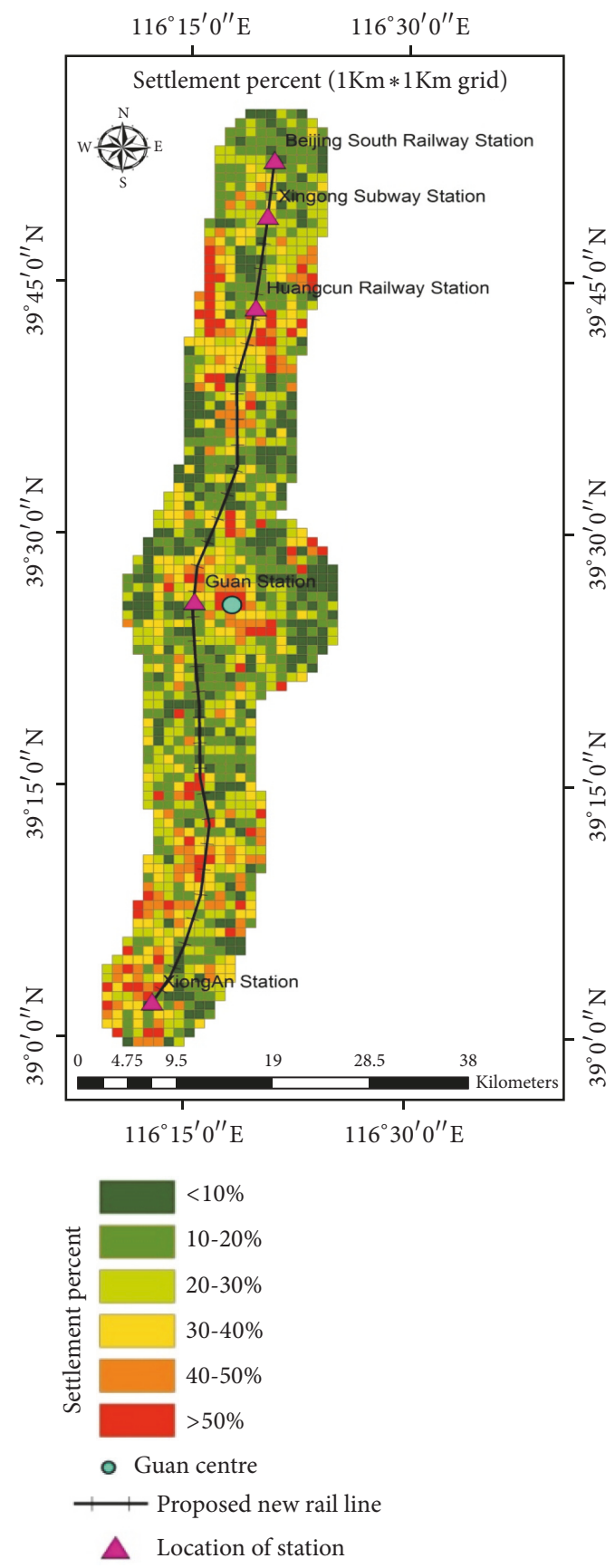

FIGURE 5: Density of settlement $(1 \mathrm{~km} * 1 \mathrm{~km}$ grid spacing) from Landsat- 8 satellite image.

or for auxiliary purposes. For high-speed trains, the reduction in electricity can be used by employing regenerative braking.

(vi) The investment costs for the construction of a new railway high-speed line are the same for all six alternatives and therefore they are not considered.

(vii) In Chinese Railways there are no infrastructure charges. Therefore, operating costs do not include infrastructure charges.

(viii) The data on the salaries of railway personnel both on the trains and at the stations and the data for maintenance and repair of the rolling stock are derived from Chinese Railways.

(ix) The average ticket price for class seats is calculated as an average of 13 USD. This is similar to the BeijingTianjin Intercity High-Speed Train which is of similar length and travel time [84].

In the study we have experimented two scenarios according to the capacity utilized on the new high-speed railway line:

(i) Scenario 1: $150 / 160$ pair trains per day.

(ii) Scenario 2: 160/180 pair trains per day. 


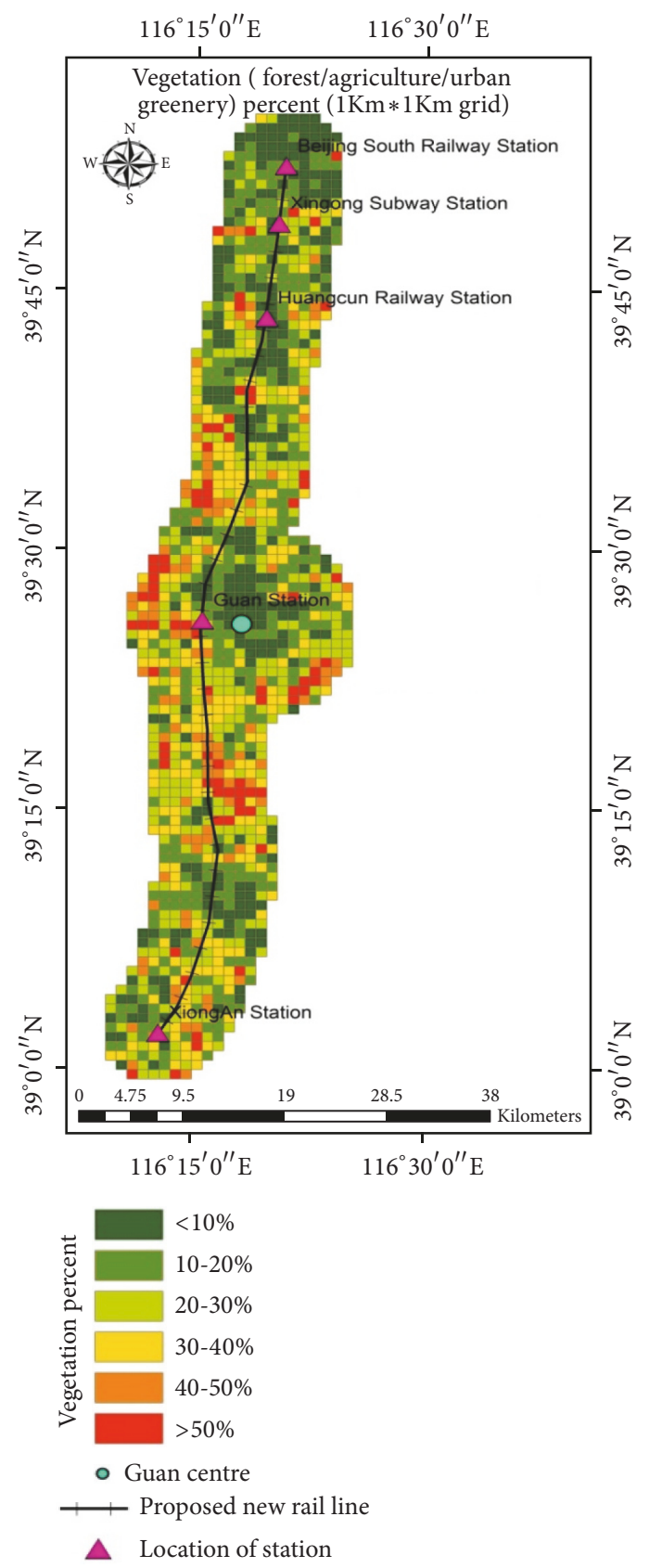

FIGURE 6: The vegetation percent $(1 \mathrm{~km} * 1 \mathrm{~km}$ grid spacing) from Landsat- 8 satellite image.

The first value presents the number of pair trains for the alternatives that do not stop in Guan (alternatives 1, 3, and 6 ); the second value presents the number of pair trains for alternatives including stopping in Guan (alternatives 2, 4, and $5)$.

Both scenarios do not exceed the maximum capacity of the new high-speed railway line. The scenarios serve as sensitivity analysis of given results.

3.2.1. First Approach. In the first approach, five criteria have been studied. The weights of each of these criteria have been determined using AHP. In this research, a group of experts gave an overall score on the scale of Saaty which is shown in Appendix A (Table 13). The group of experts consists of nine railway specialists from China Railway Corporation and Ministry of Railways with many years of experience. They were asked by the authors to give a general assessment of the pairwise comparison of the criteria using the scale of Saaty. Table 1 presents the pairwise comparison of criteria using Saaty's scale (Appendix A) and received weights. The value of consistency ratio $\mathrm{CR}=0.09$ shows that the assessment of these experts is adequate. The greatest impacts are the criteria travel time (35\%), transport satisfaction (30\%), and connectivity (20\%).

Table 2 shows the data used for the two scenarios. The values of criterion $\mathrm{Cl}$ are determined by using ArcGIS. The 


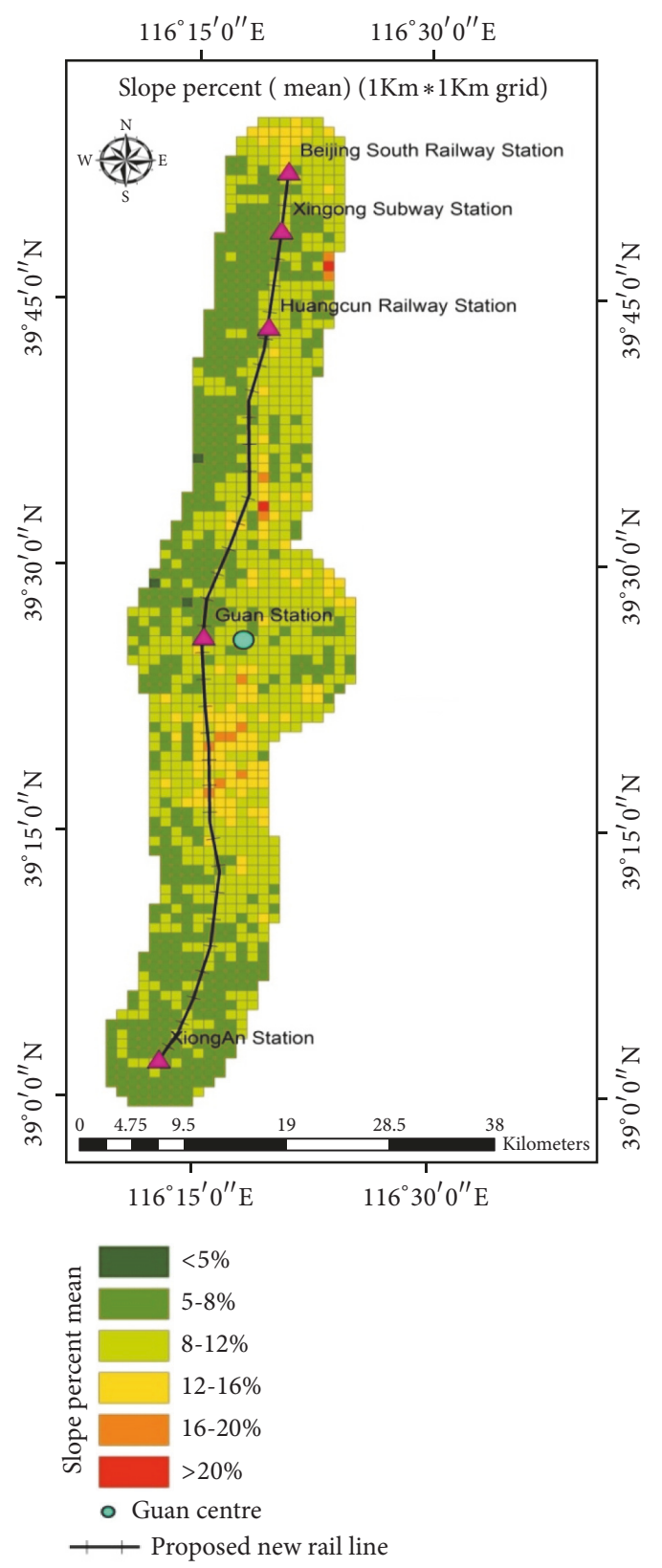

FIGURE 7: The slope percent categories derived (at $1 \mathrm{~km} * 1 \mathrm{~km}$ grid spacing) from Digital Elevation Model (DEM) image.

TABLE 1: Pairwise comparison of criteria from $\mathrm{C} 1$ to $\mathrm{C} 5$ and weights.

\begin{tabular}{|c|c|c|c|c|c|c|}
\hline Criteria & $\mathrm{C} 1$ & $\mathrm{C} 2$ & $\mathrm{C} 3$ & $\mathrm{C} 4$ & C5 & Weights \\
\hline $\mathrm{Cl}$ : Travel time, $\min$ & 1 & 4 & 2 & 5 & 1 & 0.35 \\
\hline C2: Number of train stops & $1 / 4$ & 1 & $1 / 5$ & $1 / 2$ & $1 / 3$ & 0.06 \\
\hline C3: Transport satisfaction, pair trains/day & $1 / 2$ & 5 & 1 & 4 & 2 & 0.30 \\
\hline C4: Number of seats/day & $1 / 5$ & 2 & $1 / 4$ & 1 & $1 / 2$ & 0.09 \\
\hline C5: Connectivity & 1 & 3 & $1 / 2$ & 2 & 1 & 0.20 \\
\hline
\end{tabular}




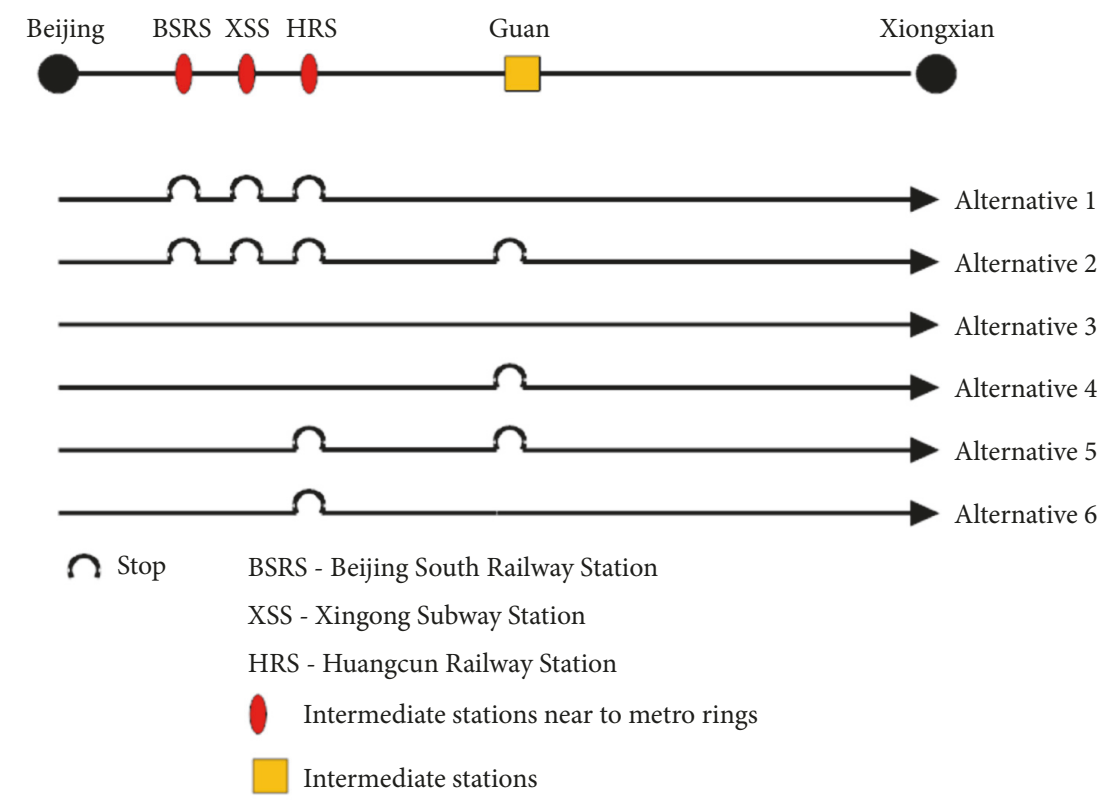

FIGURE 8: Alternatives between Beijing (start point) and Xiongan (final point).

TABLE 2: Parameters for the first approach.

\begin{tabular}{lccccccc}
\hline Alternative & C1, min & C2 & \multicolumn{2}{c}{ C3, pair trains/day } & \multicolumn{2}{c}{ C4, seats/day } \\
& & & Scenario 1 & Scenario 2 & Scenario 1 & Scenario 2 \\
\hline 1 & 36 & 3 & 150 & 160 & 180000 & 192000 & 1 \\
\hline 2 & 38 & 4 & 160 & 180 & 192000 & 216000 & 1 \\
\hline 3 & 30 & 0 & 150 & 160 & 180000 & 192000 & 0 \\
\hline 4 & 32 & 1 & 160 & 180 & 192000 & 216000 & 0 \\
\hline 5 & 34 & 2 & 160 & 180 & 192000 & 216000 & 1 \\
\hline 6 & 32 & 1 & 150 & 160 & 180000 & 192000 \\
\hline Type of optimization & min & min & max & max & max & max & max \\
\hline Type of preference function & linear & linear & linear & linear & linear & linear & usual \\
\hline
\end{tabular}

values of criterion $\mathrm{C} 2$ are put according to the number of intermediate stops for each alternative that are presented in Figure 8. These data are the inputs parameters for PROMETHEE II. The criterion of choosing the best alternative is the maximum net outranking flows. PROMETHEE II method uses six types of preference functions. The type of optimization of the criteria and preference function for this study are given it the last rows in Table 2.

Figure 9 presents the ranking of alternatives by first approach using Visual PROMEHEE software. The Visual PROMETHEE uses PROMETHEE II method to find the best solution. Figure 9 contains two parts. The first part presents the PROMETHEE II outranking flows; the second part shows the weight of each criterion. The research has been conducted separately for each scenario. The results are the same. It can be seen that the optimal alternative, in this case, is alternative 5 which involves stopping in Guan.

Table 3 presents the values of PROMETHEE II score (net outranking flows) and the ranking of alternatives. Alternative 5 has the maximal value of net outranking flows and is the best for this approach.
Table 4 shows the sensitivity analysis of the results given by Visual PROMETHEE software. Here we present the limits of changing the weights of the criteria while preserving the best solution. The "weight" column in Table 4 shows the weights obtained from AHP method. The "minimum" and "maximum weight" columns indicate the range of weights, such that the ranking of the alternatives remains unchanged. A larger weight stability interval indicates that it could have large effect on the ranking. It can be seen that the criteria C3 (transport satisfaction, trains/day) and C4 (number of seats/day) have large stability intervals.

3.2.2. Second Approach. The best alternative is chosen by taking into account both the impact of the costs presented by criteria C6-C8 and the complex effect of the benefits presented by criteria $\mathrm{C} 1-\mathrm{C} 5$. The criteria $\mathrm{C} 6-\mathrm{C} 8$ are not introduced into the PROMETHEE II model. The impact of these criteria is examined separately; the choice of the best alternative is made by using a complex criterion. The parameters of both scenarios are given in Table 5. In this approach, all defined criteria, $\mathrm{C} 1-\mathrm{C} 8$, have been taken into 

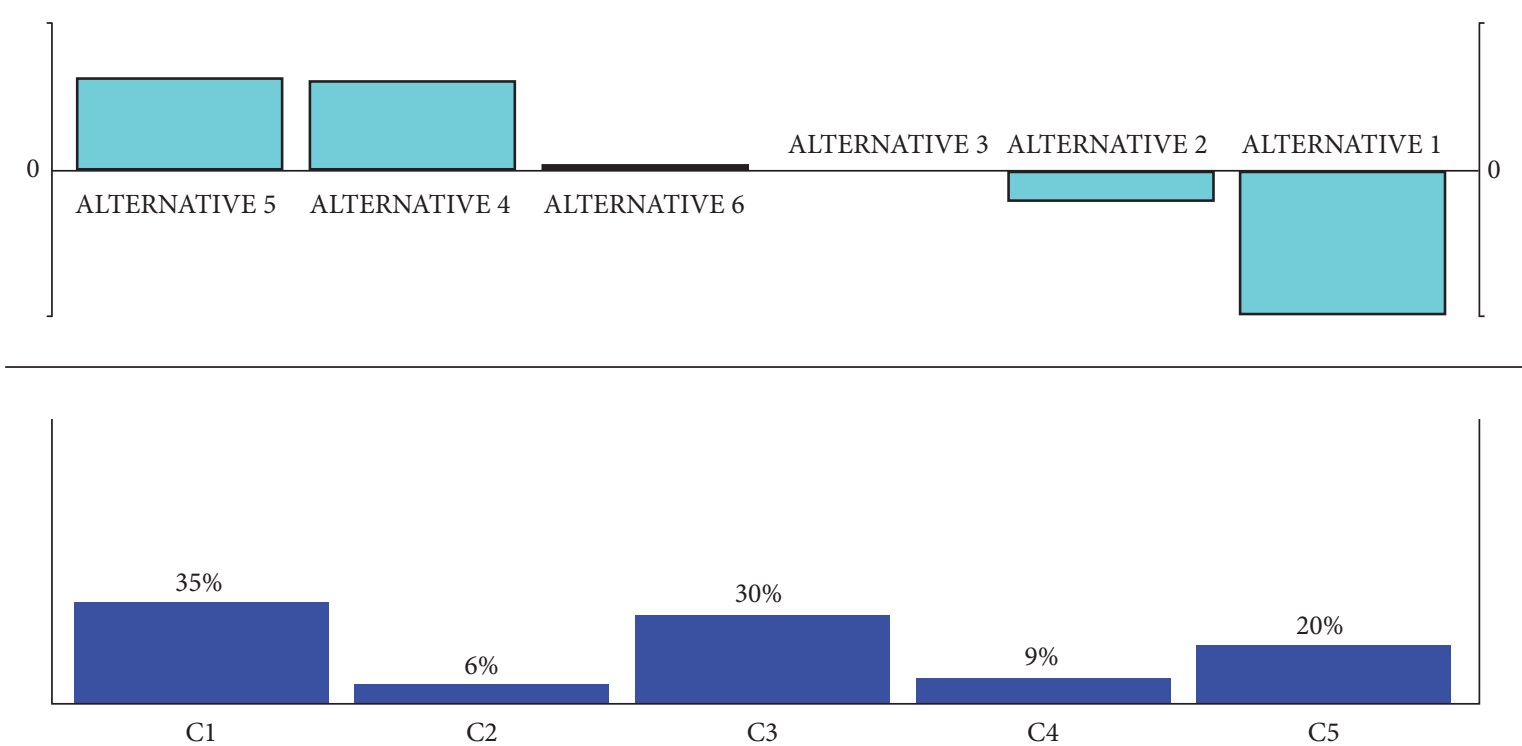

FIGURE 9: Ranking of alternatives on criteria C1 to C5 (results in Visual PROMETHEE software).

TABLE 3: Net outranking flows for the first approach.

\begin{tabular}{lcccccccc}
\hline & & \multicolumn{4}{c}{ Alternatives } \\
& Criterion & Scenario & 1 & 2 & 3 & 4 & 5 \\
\hline First approach & Net outranking flows & $1 ; 2$ & -0.400 & -0.084 & -0.008 & 0.238 & 0.244 & 0.01 \\
& rank & & 6 & 5 & 4 & 2 & 1 \\
\hline
\end{tabular}

account. Tables 6 and 7 present the values of criteria for both scenarios. The values of the criteria were determined by formulas (2) and (7). The values of net outranking flows are shown in Tables 6 and 7. It can be seen that in both scenarios the best alternative by criterion $\mathrm{r}_{\mathrm{f} 1}$-ratio of the normalized operating costs and the normalized net outranking flows-is alternative 5; the values of this criterion for alternatives 5 and 4 are close. Alternative 3 is optional by criterion $\mathrm{r}_{\mathrm{f} 2}$-ratio of the normalized values of the payback period and the normalized net outranking flows. The last columns of Tables 6 and 7 present the ranking of alternatives for both scenarios.

The real contribution of the second approach is the definition of two new complex criteria for choosing the best alternative. These criteria present the ratio of costs and benefits. The determination of the score of benefits is made by using multicriteria analysis: AHP method to evaluate the criteria and PROMETHEE II method for assessing and ranking the alternatives. In this case is used only criteria C1C5. The other assessment is made according to the criteria presenting the costs. For this purpose two different criteria have been introduced: normalized operating costs and normalized payback period. The final ranking of alternatives is made by using complex criterion that considered both costs and benefits. Two complex criteria have been defined. The first considers the impact of operating costs, the second takes into account the impact of investment, revenue, and operating cost. These criteria serve the comparison of results.
3.2.3. Third Approach. In this approach, all the criteria have been used.

The type of optimization of the criteria and preference function for this study are given in the last rows in Tables 8 and 9.

Table 10 presents the pairwise comparison of the criteria and received results of weights. The scores are given by the same group of nine experts. The value of consistency ratio $\mathrm{CR}=0.08$ (Appendix A, Table 14 ) shows that the assessment of the experts is adequate. The greatest impacts are upon the criteria connectivity (19\%), travel time (15\%), profit (15\%), transport satisfaction (16\%), and payback period (14\%).

The optimization criterion is the maximum of the PROMETHEE II score-maximum net outranking flows. Figures 10 and 11 show the results of optimization using Visual PROMETHEE software for both scenarios. In the first parts of the figures we show the PROMETHEE II net outranking flows; in the second parts we present the weights of criteria used.

In this approach, the best alternative for scenario 1 is alternative 5 , for scenario 2 , it is alternative 4 . It can be seen that for scenario 2 the results for alternative 4 and alternative 5 are close. For both alternatives there is a stop in Guan.

Table 11 shows the sensitivity analysis of the results given by Visual PROMETHEE software. Here we present the limits of changing the weights of the criteria while preserving the optimal solution for both scenarios. It can be seen that the criteria C1 (travel time) and C2 (number of train stops) 
TABLE 4: Limits of changing the weights of the criteria related to the trips while preserving the optimal solution.

\begin{tabular}{lcccc}
\hline Criteria & Weight, $\%$ & Minimum weight, $\%$ & Maximum weight, $\%$ & Range difference, $\%$ \\
\hline C1 & 35 & 32.43 & 35.64 & 3.21 \\
\hline C2 & 6 & 0.60 & 7.39 & 6.79 \\
\hline C3 & 30 & 13.58 & 34.17 & 20.59 \\
\hline C4 & 9 & 0.00 & 14.42 & 14.42 \\
\hline C5 & 20 & 19.60 & 24.76 & 5.16 \\
\hline
\end{tabular}

TABLE 5: Parameters of the alternatives.

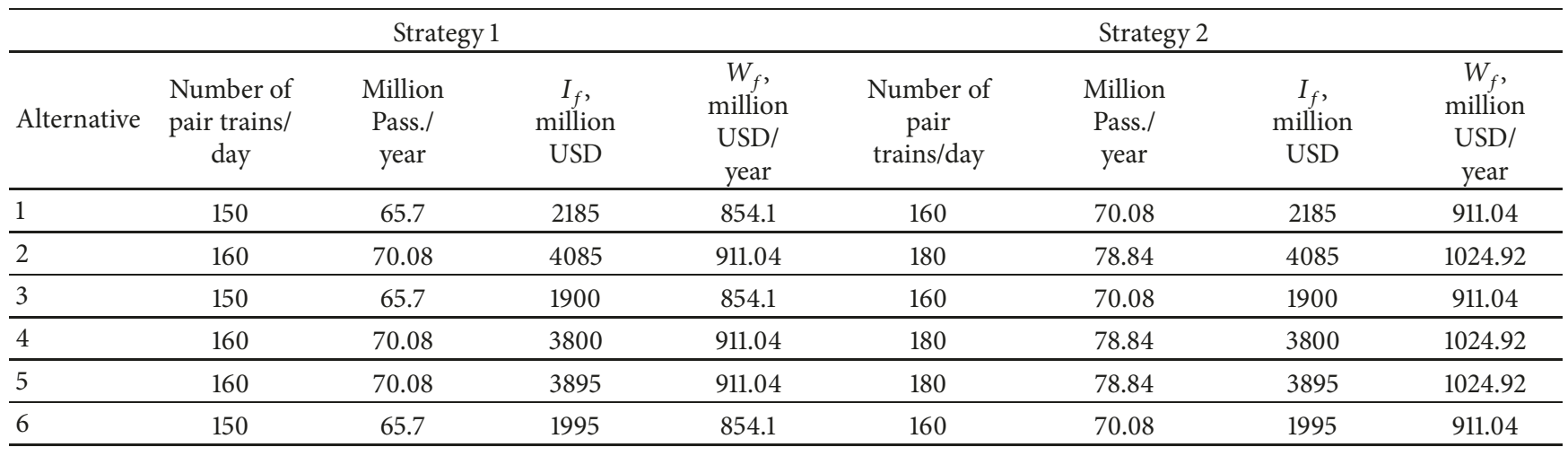

TABLE 6: Results for optimization criteria, Scenario 1.

\begin{tabular}{|c|c|c|c|c|c|c|c|c|}
\hline \multicolumn{9}{|c|}{ Scenario 1} \\
\hline Alternative & $p_{f}$ & $c_{f}$ & $r_{1 f}$ & $r_{2 f}$ & $\varphi_{f}$ & $a_{f}$ & Rank By $r_{1 f}$ & Rank by $r_{2 f}$ \\
\hline 1 & 0.128 & 0.162 & 1.615 & 1.277 & -0.400 & 0.100 & 6 & 5 \\
\hline 2 & 0.224 & 0.172 & 1.130 & 1.468 & -0.084 & 0.153 & 5 & 6 \\
\hline 3 & 0.111 & 0.161 & 0.973 & 0.670 & -0.008 & 0.165 & 4 & 1 \\
\hline 4 & 0.208 & 0.172 & 0.833 & 1.007 & 0.238 & 0.206 & 2 & 3 \\
\hline 5 & 0.213 & 0.172 & 0.830 & 1.028 & 0.244 & 0.207 & 1 & 4 \\
\hline 6 & 0.116 & 0.161 & 0.957 & 0.691 & 0.010 & 0.168 & 3 & 2 \\
\hline
\end{tabular}

have large stability intervals for which the ranking remains unchanged.

3.2.4. Choosing the Suitable Alternative. In this research the defined approaches and scenarios serve to make sensitivity analysis in regard to choice of suitable alternative.

Table 12 presents the ranking of the alternatives according to each approach and its scenarios. It contains the rank of each alternative and approach according to the defined criteria of choosing the best alternative. The results of ranking for the first approach are taken from Table 3; the results for the second approach, respectively, from Tables 7 and 8; and the results for the third approach according to Tables 9 and 10. Figure 12 presents a comparison of results.

The results show the following:

(i) Alternative 5 is the best one by the first approach and both scenarios, when applying only criteria connected to transportation $\mathrm{C} 1-\mathrm{C} 5$. The second position is for alternative 4 . In this case, the economic criteria are not taken into account, which is the reason for the sustainability of the solution for both strategies. (ii) The best alternative for the second approach is different for both criteria. The results show that alternative 5 is the best one by using the criterion $r_{1 f}$, the ratio between the normalized operating costs and the normalized net outranking flows corresponding to the PROMETHEE II priority. The best alternative by criterion $r_{2 f}$, the normalized values of the payback period and the normalized net outranking flows corresponding to the PROMETHEE II priority, is alternative 3. The difference in ranking is due to the parameters that are considered in both criteria. The second criterion besides the operating costs considers investment and revenues of transportation. This is the reason for the change in the ranking of alternatives. Alternative 3 has minimum investment costs and payback period for both scenarios.

(iii) The best alternative for the third approach when applying all criteria is alternative 5 for the first scenario; the best alternative for the second scenario is alternative 4 . These alternatives differ in the number of stops, but both have a stop at the proposed new station Guan. 
TABLE 7: Results for optimization criteria, Scenario 2.

\begin{tabular}{lcccccccc}
\hline \multicolumn{7}{c}{ Scenario 2} \\
\hline Alternative & $p_{f}$ & $c_{f}$ & $r_{1 f}$ & $r_{2 f}$ & $\varphi_{f}$ & $a_{f}$ & Rank by $r_{1 f}$ & Rank by $r_{2 f}$ \\
\hline 1 & 0.132 & 0.157 & 1.570 & 1.320 & -0.400 & 0.100 & 6 \\
\hline 2 & 0.220 & 0.177 & 1.157 & 1.438 & -0.084 & 0.153 & 5 \\
\hline 3 & 0.115 & 0.157 & 0.952 & 0.697 & -0.008 & 0.165 & 3 & 2 \\
\hline 5 & 0.204 & 0.176 & 0.854 & 0.990 & 0.238 & 0.206 & 2 & 1 \\
\hline 6 & 0.209 & 0.176 & 0.850 & 1.010 & 0.244 & 0.207 & 4 \\
\hline
\end{tabular}

TABle 8: Parameters for the second approach, Scenario 1.

\begin{tabular}{lcccccccc}
\hline Criteria & C1 & C2 & C3 & C4 & C5 & C6 & C7 & C8 \\
\hline Alternative & min & stop & pair trains/day & seats/day & coef. & million USD/year & million USD/year & year \\
1 & 36 & 3 & 150 & 180000 & 1 & 413.64 & 440.46 & 4 \\
\hline 2 & 38 & 4 & 160 & 192000 & 1 & 441.71 & 469.33 & 8.7 \\
\hline 3 & 30 & 0 & 150 & 180000 & 0 & 412.16 & 441.94 & 4.3 \\
\hline 4 & 32 & 1 & 160 & 192000 & 0 & 440.15 & 470.89 & 470.37 \\
\hline 5 & 34 & 2 & 160 & 192000 & 1 & 440.67 & 8.3 \\
\hline 6 & 32 & 1 & 150 & 180000 & 1 & 412.65 & 441.45 & 4.5 \\
\hline Type of optimization & min & min & max & max & max & min & max \\
\hline Preference function & linear & linear & linear & linear & usual & linear & linear & linear \\
\hline
\end{tabular}

TABLE 9: Parameters for the second approach, Scenario 2.

\begin{tabular}{lcccccccc}
\hline Criteria & C1 & C2 & C3 & C4 & C5 & C6 & C7 \\
\hline Alternative & min & stop & pair trains/day & seats/day & coef. & million USD/year & million USD/year & year \\
1 & 36 & 3 & 160 & 192000 & 1 & 441.19 & 469.85 & 4.65 \\
\hline 2 & 38 & 4 & 180 & 216000 & 1 & 496.86 & 528.06 & 7.74 \\
\hline 3 & 30 & 0 & 160 & 192000 & 0 & 439.64 & 471.4 & 4.03 \\
\hline 4 & 32 & 1 & 180 & 216000 & 0 & 495.16 & 529.76 & 7.17 \\
\hline 5 & 34 & 2 & 180 & 216000 & 1 & 495.72 & 7.36 \\
\hline 6 & 32 & 1 & 160 & 192000 & 1 & 440.15 & 470.89 & 4.24 \\
\hline Type of optimization & min & min & max & max & max & min & max \\
\hline Preference function & linear & linear & linear & linear & usual & linear & linear & linear \\
\hline
\end{tabular}

TABLE 10: Pairwise comparison of criteria and weights.

\begin{tabular}{lcccccccccc}
\hline Criteria & C1 & C2 & C3 & C4 & C5 & C6 & C7 & C8 & weights \\
\hline C1: Travel time, min & 1 & 4 & 2 & 5 & 1 & $1 / 2$ & $1 / 2$ & $1 / 2$ & 0.15 \\
\hline C2: Number of train stops & $1 / 4$ & 1 & $1 / 5$ & $1 / 2$ & $1 / 5$ & $1 / 2$ & $1 / 3$ & $1 / 3$ & 0.04 \\
\hline C3: Transport satisfaction, pair trains/day & $1 / 2$ & 5 & 1 & 3 & 2 & 2 & 1 & 1 & 0.16 \\
\hline C4: Number of seats/day & $1 / 5$ & 2 & $1 / 3$ & 1 & $1 / 5$ & $1 / 2$ & 1 & $1 / 2$ & 0.06 \\
\hline C5: Connectivity & 1 & 5 & $1 / 2$ & 5 & 1 & 2 & 1 & 3 & 0.19 \\
\hline C6: Operating costs, million USD/year & 2 & 2 & $1 / 2$ & 2 & $1 / 2$ & 1 & $1 / 3$ & 1 \\
\hline C7: Profit, million USD/year & 2 & 3 & 1 & 1 & 1 & 3 & 1 & $1 / 2$ & 0.10 \\
\hline C8: Payback Period, years & 2 & 3 & 1 & 2 & $1 / 3$ & 1 & 2 & 1 \\
\hline CR:0.08 & & & & & & & & & & \\
\hline
\end{tabular}

The investigated approaches for choosing the best alternative between compared ones use different criteria for decision making. They can be used to compare the results given by applying each of them.
It can be seen that alternative 5 is the best for scenario 1 for the three approaches. There is a difference in the results for the second scenario among the different approaches. In this case alternative 3 is the best when using the second approach 

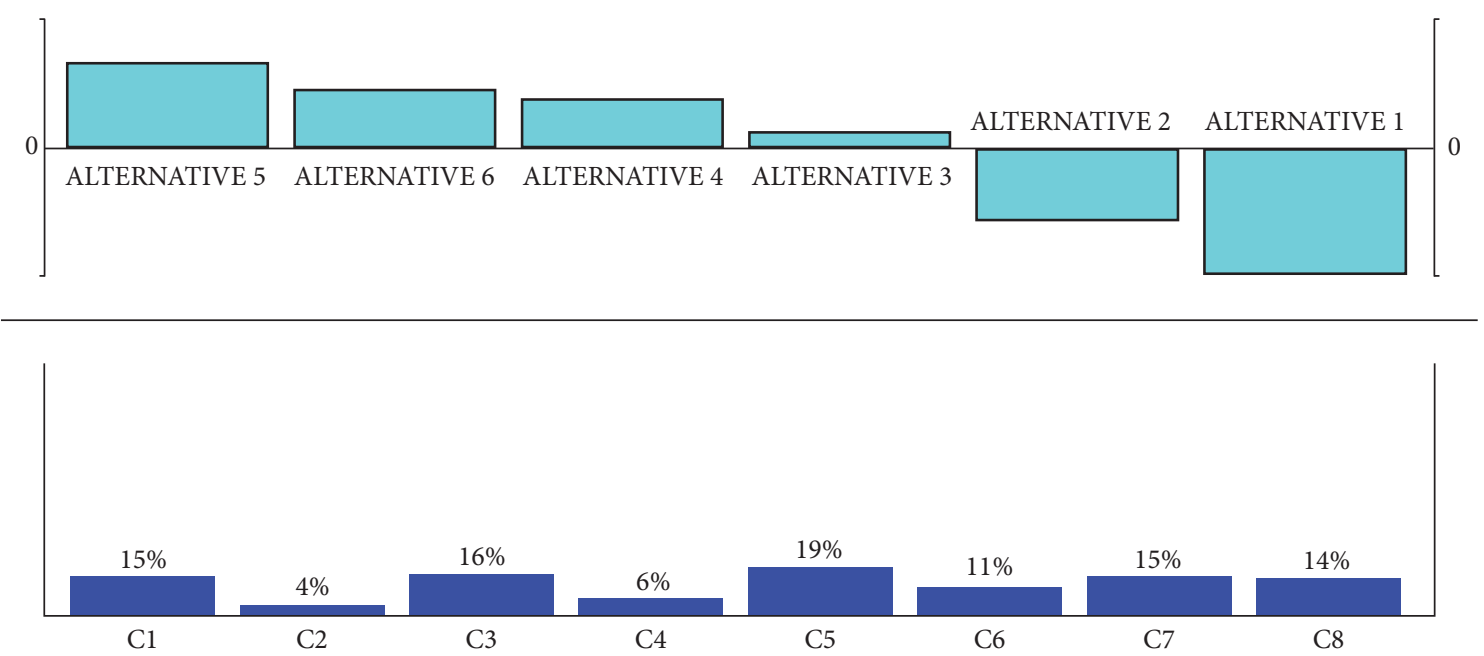

FIGURE 10: Ranking of alternatives for scenario 1, results in Visual PROMETHEE software.
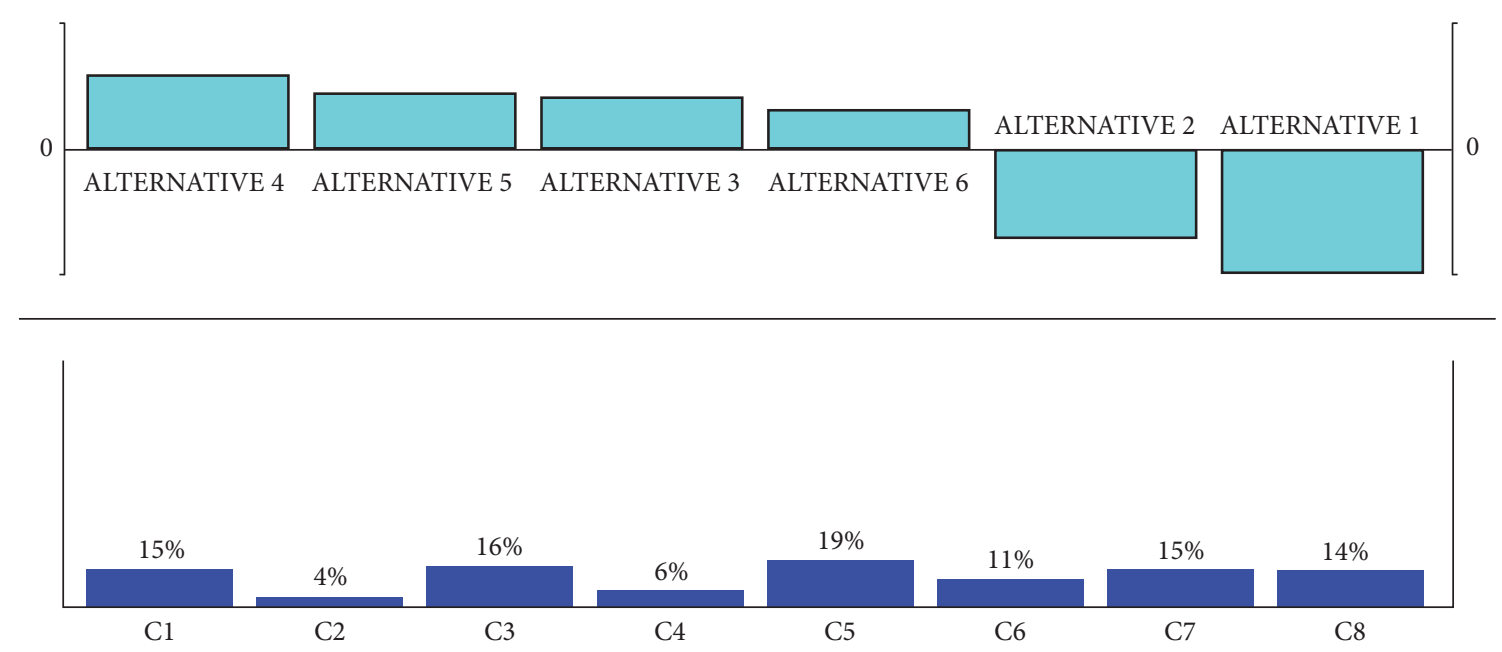

FIGURE 11: Ranking of alternatives for scenario 2, results in Visual PROMETHEE software.

and criterion $r_{2 f}$ to select the best one. This is explained by the little needed investments for this alternative. Alternative 4 is the best one for the third approach.

It can be concluded that with the increment of the number of trains in second scenario, the suitable alternative is changed. The application of the criterion ratio of the normalized values of the payback period and the normalized outranking flows given by PROMETHEE II as the tools of ranking alternatives leads to change in the suitable decision. The change in ranking indicates that additional alternatives could be explored, with combined services in terms of number of stops at intermediate stations; for example, some trains stopped in Guan, and others stopped in both HRS station and Guan; or some trains do not stop anywhere on the route, others stop in Guan, and others stop in both HRS station and Guan.

The first approach considered the effect of only the criteria related to transportation. It could be used for preliminary analyses when there is not information on operating costs and other economic criteria. The second approach takes into account both transportation and economic criteria. It uses two new criteria to assess the alternatives. This approach could be used when the decision maker wishes to make a decision through the cost-benefit ratio. The benefits are determined by transportation criteria by using multicriteria analysis. The costs are determined as operating costs or as a payback period. The third approach takes into account the impact of both transportation criteria and economic criteria in multicriteria model. It could be used to make decision about investigated alternatives.

Finally we can conclude that alternative 5 is defined in most of the investigated cases as the suitable one.

That is why we choose, as the suitable alternative for transportation, the variant where the trains have a stop in metro ring (Huangcun railway station) and also in Guan-alternative 5. This alternative provides an extension of Huangcun railway station and construction of a new railway station, Guan. The extension of Huangcun railway station for high-speed transport will contribute to the convenience of passengers to use the new service. The introduction of a new 
TABLE 11: Limits of changing the weights of all the criteria while preserving the best solution.

\begin{tabular}{|c|c|c|c|c|c|c|c|}
\hline \multirow[b]{2}{*}{ Criteria } & \multirow[b]{2}{*}{ Weight,\% } & \multicolumn{3}{|c|}{ Scenario 1} & \multicolumn{3}{|c|}{ Scenario 2} \\
\hline & & $\begin{array}{l}\text { Minimum } \\
\text { weight, \% }\end{array}$ & $\begin{array}{l}\text { Maximum } \\
\text { weight, } \\
\%\end{array}$ & $\begin{array}{c}\text { Range } \\
\text { difference, } \\
\%\end{array}$ & $\begin{array}{l}\text { Minimum } \\
\text { weight, \% }\end{array}$ & $\begin{array}{c}\text { Maximum } \\
\text { weight, } \\
\%\end{array}$ & $\begin{array}{c}\text { Range } \\
\text { difference, } \\
\%\end{array}$ \\
\hline $\mathrm{C} 1$ & 15 & 10.53 & 15.56 & 5.03 & 9.19 & 20.06 & 10.87 \\
\hline $\mathrm{C} 2$ & 4 & 0.00 & 5.26 & 5.26 & 0.00 & 12.33 & 12.33 \\
\hline $\mathrm{C} 3$ & 16 & 15.44 & 31.61 & 16.17 & 13.25 & 16.83 & 3.58 \\
\hline $\mathrm{C} 4$ & 6 & 5.37 & 23.47 & 18.10 & 2.93 & 6.93 & 4.00 \\
\hline C5 & 19 & 18.46 & 20.98 & 2.52 & 18.18 & 26.81 & 8.63 \\
\hline C6 & 1 & 3.78 & 11.44 & 7.66 & 10.33 & 13.73 & 3.40 \\
\hline $\mathrm{C} 7$ & 15 & 14.14 & 36.69 & 22.55 & 12.22 & 15.63 & 3.41 \\
\hline $\mathrm{C} 8$ & 14 & 7.03 & 14.43 & 7.40 & 12.69 & 16.64 & 3.95 \\
\hline
\end{tabular}

TABLE 12: Rank of priorities of the alternatives.

\begin{tabular}{|c|c|c|c|c|c|c|c|c|}
\hline & & & \multicolumn{6}{|c|}{ Alternatives } \\
\hline & Criterion & Scenario & 1 & 2 & 3 & 4 & 5 & 6 \\
\hline First approach & $\varphi 1$ & 1,2 & 6 & 5 & 4 & 2 & 1 & 3 \\
\hline \multirow{3}{*}{ Second approach } & \multirow{2}{*}{$r_{1 f}$} & 1 & 6 & 5 & 4 & 2 & 1 & 3 \\
\hline & & 2 & 6 & 5 & 3 & 2 & 1 & 4 \\
\hline & $r_{2 f}$ & 1,2 & 5 & 6 & 1 & 3 & 4 & 2 \\
\hline \multirow{2}{*}{ Third approach } & \multirow{2}{*}{$\varphi 2$} & 1 & 6 & 5 & 2 & 3 & 1 & 2 \\
\hline & & 2 & 6 & 5 & 4 & 1 & 2 & 3 \\
\hline
\end{tabular}

station will increase travel and help to expand the satellite cities of Beijing.

In further researches we would expand the scope of the alternatives studied. This study demonstrates the applicability of proposed methodology which uses multicriteria analysis as an appropriate tool for decision making.

\section{Conclusion}

This research focuses on multicriteria and GIS decision approaches to determine the best alternative. The results from Remote Sensing and GIS analysis show that the proposed high-speed railway line will be economically/socially feasible and that it will satisfy the needs of significant numbers of current and future passengers. The criteria to assess the alternatives of transportation have been determined. The alternatives have been defined according to the stops in the high-speed railway line. A new railway station, Guan, has been proposed. It was found that when taking into account only the criteria related to transportation $\mathrm{C1}-\mathrm{C} 5$ in the first approach, the greatest impacts are the criteria travel time (35\%), transport satisfaction (30\%), and connectivity (20\%). The greatest impacts are upon the criteria connectivity (19\%), travel time (15\%), profit (15\%), transport satisfaction $(16 \%)$, and payback period (14\%) when taking into account all criteria in the third approach. Two scenarios of passenger transport satisfaction were examined. The methodology proposed in this paper examines three approaches to decision making. The first considers only the effect on the criteria related to trips which were included in the PROMETHEE II model. It was found that alternative 5 is the best one.
This alternative provides transportation between Beijing and Xiongan with intermediate stops in Guan and a third ring of the metro to meet the needs of passenger traffic. The effect of both criteria related to the trips and economic criteria have been studied in the second approach. Two criteria for choosing the best alternative have been proposed; one presents the ratio of normalized values of operating costs and normalized values of net outranking flows by PROMETHEE II method; the other presents the ratio of normalized values of payback period and normalized values of net outranking flows by PROMETHEE II method. The results show that alternative 5 is the suitable one by using the criterion of the ratio between the normalized operating costs and the normalized net outranking flows. The suitable alternative by the criterion of the normalized values of the payback period and the normalized net outranking flows is alternative 3. This alternative delivers direct transport without intermediate stops from Beijing to Xiongan. The third approach includes all investigated criteria into the PROMEHEE II model. The results for the two scenarios include stopping in Guan city (alternative 4 for scenario 2 and alternative 5 for scenario 1). The final decision is made by comparing the results of the three approaches. Finally we can conclude that alternative 5 is defined by the different approaches as the suitable one. This alternative presents a stop in metro ring (Huangcun railway station) and also in Guan-alternative 5. This alternative provides an extension of Huangcun railway station and construction of a new railway station, Guan. The result indicates that it is expedient to have a station in Guan, which will increase connection 


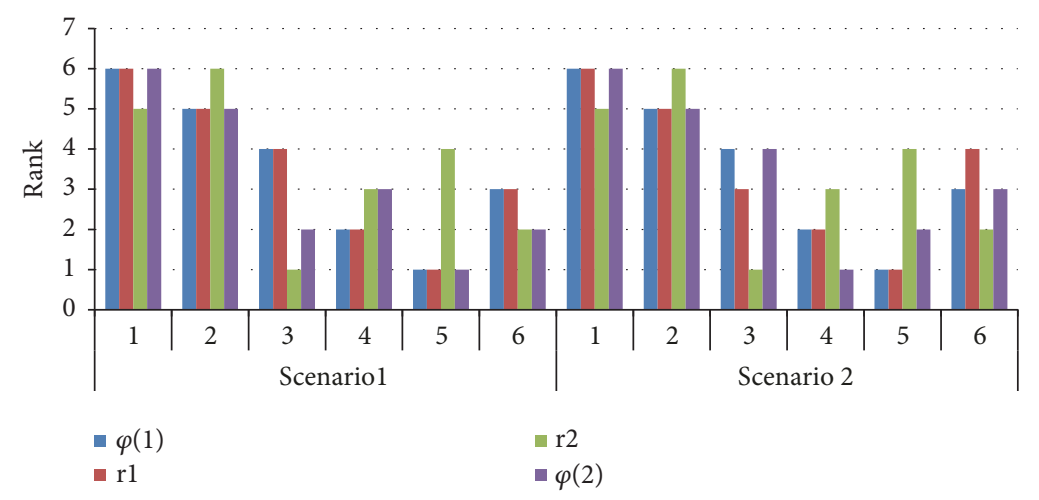

FIGURE 12: Ranking of the alternatives for scenarios 1 and 2.

TABLE 13: Saaty's scale for pairwise comparison.

\begin{tabular}{|c|c|}
\hline $\begin{array}{l}\text { Intensity of } \\
\text { importance }\end{array}$ & Definition \\
\hline 1 & Equal importance \\
\hline 3 & $\begin{array}{c}\text { Moderate importance of one factor over } \\
\text { another }\end{array}$ \\
\hline 5 & Strong or essential importance \\
\hline 7 & Very strong importance \\
\hline 9 & Extreme importance \\
\hline $2,4,6,8$ & Values for intermediate comparison \\
\hline
\end{tabular}

and connectivity among cities while providing fast mobility options to the large number of inhabitants of Guan. Our results point to the desirability of a strategy related to highspeed rail transportation between Beijing and Xiongan. This transportation will improve the mobility around and between these cities and the development of the cities themselves. The proposed methodology in this paper can be applied to make research for other conventional and high-speed rail.

Further research should consider more criteria to establish a better and more highly refined model. The investigated problem could be expanded to explore mixed service on the new high-speed railway line.

\section{Appendix}

\section{A. AHP Method for Determining the Weights of Criteria}

This method uses pairwise comparisons between criteria by Saaty's scale [85] of nine levels as shown in Table 13.

The elements of evaluation matrix $A$ of the pairwise comparison of $n$ criteria consist of $(n, n)$ elements which have the following relationships:

$$
\begin{aligned}
& a_{i i}=1 ; \\
& a_{i j} \neq 0 ; \\
& a_{j i}=\frac{1}{a_{i j}}
\end{aligned}
$$

where $a_{i j}(i, j=1, \ldots, n)$ are the elements of the evaluation matrix.

The relative weights are given by the normalized right eigenvector $\left(W=\left\{w_{1}, . ., w_{n}\right\}^{T}\right)$ associated with the largest eigenvalue $\left(\lambda_{\max }\right)$ of the square matrix $A$.

The largest eigenvalue $\left(\lambda_{\max }\right)$ is calculated as follows.

$$
\begin{aligned}
& A W=\lambda_{\text {max }} \cdot W \\
& \lambda_{\max }=\sum_{i=1}^{n}\left[\left(\sum_{j=1}^{n} a_{i j}\right) \cdot W_{i}\right]
\end{aligned}
$$

The adequacy of an expert's assessment is determined by the consistency ratio:

$$
C R=\frac{C I}{R I} \leq 0,1
$$

where $C I$ is the consistency index and $R I$ is a random index. The random matrix is given by Saaty [86]. Its values are shown in Table 14.

The consistency index is as follows.

$$
C I=\frac{\lambda_{\max }-n}{n-1}
$$

\section{B. PROMETHEE II Method for Ranking Alternatives}

This method is based on a comparison of pair-by-pair possible decisions along each criterion. Possible decisions are evaluated according to different criteria, which have to be maximized or minimized. The use of the PROMETHEE II method requires two additional types of information for each criterion i: a weight $\mathrm{w}_{\mathrm{i}}$ and a preference function $\mathrm{P}_{\mathrm{i}}(\mathrm{a}, \mathrm{b})$. Preference function $\mathrm{P}_{\mathrm{i}}(\mathrm{a}, \mathrm{b})$ depends on a pairwise difference between the evaluations $\mathrm{f}_{\mathrm{i}}(\mathrm{a})$ and $\mathrm{f}_{\mathrm{i}}(\mathrm{b})$ of alternatives $a$ and $b$ for criterion $i$. The preference function characterizes the difference for a criterion between the evaluations obtained by two possible decisions into a preference degree ranging from 0 to 1 . In order to facilitate the definition of these functions, six basic preference functions have been proposed: usual criterion; quasi criterion; criterion with linear preference; level criterion; criterion with linear preference and 
TABLE 14: Random consistency index (RI).

\begin{tabular}{|c|c|c|c|c|c|c|c|c|c|c|c|c|c|c|c|}
\hline $\mathrm{n}$ & 1 & 2 & 3 & 4 & 5 & 6 & 7 & 8 & 9 & 10 & 11 & 12 & 13 & 14 & 15 \\
\hline RI & 0 & 0 & 0.58 & 0.9 & 1.12 & 1.24 & 1.32 & 1.41 & 1.45 & 1.49 & 1.51 & 1.48 & 1.56 & 1.57 & 1.59 \\
\hline
\end{tabular}

indifference area; and Gaussian criterion. The explanation and mathematical calculation steps of the PROMETHEE II method are summarized below $[79,87,88]$.

Step 1. The preference degree is computed for each pair of possible decisions and for each criterion, the value of e.

Step 2. For each pair of possible decisions, a global preference index $\pi(a, b)$ has to be calculated:

$$
\pi(\mathrm{a}, \mathrm{b})=\frac{\sum_{\mathrm{i}=1}^{\mathrm{n}} \mathrm{w}_{\mathrm{i}} \cdot \mathrm{P}_{\mathrm{i}}(\mathrm{a}, \mathrm{b})}{\sum_{\mathrm{i}}^{\mathrm{n}} \mathrm{w}_{\mathrm{i}}}
$$

where $\mathrm{i}=1, \ldots, \mathrm{n}$ is the number of criteria.

Step 3. This step includes ranking of the possible decisions and inclusion of the computing of the outranking flows. For each possible decision the positive outranking flow $\phi^{+}(\mathrm{a})$ and the negative outranking flow $\varphi^{-}$(a) are computed:

$$
\begin{aligned}
\phi^{+}(a) & =\frac{\pi(a, b)}{m-1} \\
\varphi^{-}(a) & =\frac{\pi(b, a)}{m-1}
\end{aligned}
$$

where $j=1, \ldots, m$ is the number of alternatives.

Step 4. This step includes determination of net outranking flows which are used to establish a complete ranking between the possible decisions. The net outranking flow $\varphi\left(\mathrm{a}_{\mathrm{j}}\right)$ of $\mathrm{a}_{\mathrm{j}}$ in the alternatives set $\mathrm{m}$ of a possible decision is computed as a difference between $\varphi^{+}\left(\mathrm{a}_{\mathrm{j}}\right)$ and $\varphi^{-}\left(\mathrm{a}_{\mathrm{j}}\right)$.

$$
\varphi\left(\mathrm{a}_{\mathrm{j}}\right)=\varphi^{+}\left(\mathrm{a}_{\mathrm{j}}\right)-\varphi^{-}\left(\mathrm{a}_{\mathrm{j}}\right)
$$

For net outranking flow, the following conditions are valid.

$$
\begin{aligned}
\varphi\left(\mathrm{a}_{\mathrm{j}}\right) & \in[-1 ; 1] \\
\sum_{j=1}^{m} \varphi\left(\mathrm{a}_{\mathrm{j}}\right) & =0
\end{aligned}
$$

The highest value of the net outranking flow shows the best decision.

\section{Data Availability}

We have not used any confidential data, and the reference or web-link is given with each parameter or data. Only the assessment survey was done manually, and its hard copy is available.

\section{Conflicts of Interest}

The authors declare no conflicts of interest.

\section{Authors' Contributions}

The main framework for the research study was developed by Asim Farooq and Svetla Stoilova, while Mowen Xie contributed to the survey and collection of data, and Firoz Ahmad, Asim Farooq, and Svetla Stoilova analyzed the data and modeled the figures. We would like to thank Mark Buck and Edward Williams for the valuable comments and for proofreading the article.

\section{Acknowledgments}

The authors gratefully acknowledge the financial support from the National Natural Science Foundation of China under Grant no. 41572274, China Postdoctoral Science Foundation under Grant no. 2016M591078, and the Fundamental Research Funds for the Central Universities of China under Grant no. FRF-TP-16-014A1.

\section{References}

[1] G. G. Chen, "Xiongan: a new city for the xi jinping era," The Diplomat, 2017, http://thediplomat.com/2017/05/xiongana-new-city-for-the-xi-jinping-era/.

[2] Xinhua, "China to create xiongan new area in hebei," Xinhuanet News, 2017, http://www.hxen.com/englishnews/nation/201704-02/463436.html.

[3] Chinadaily, "Central government to further shift non-essential functions out of Beijing," China Daily Beijing Municipal, China, 2017, http://www.chinadaily.com.cn/beijing/2015-02/16/ content_19602930.htm \#.

[4] E. Rosenthal, "Three lessons the xiongan project can learn from tianjin," IHC GLOBAL (inclusive housing and sustainable communities globally), 2017, https://ihcglobal.org/2017/07/17/3lessons-the-xiongan-project-can-learn-from-tianjin/.

[5] Z. Shao, The New Urban Area Development (A Case Study in China), Springer Verlag, Berlin, Germany, 2015.

[6] L. Qin, "Xiong'an new district: an old idea is finally accepted," China Dialogue, 2017, https://www.chinadialogue.net/culture/ 9937-Xiong-an-New-District-An-old-idea-is-finally-accepted/ en.

[7] Z. Wang, J. Chen, W. Zheng, and X. Deng, "Dynamics of land use efficiency with ecological intercorrelation in regional development," Landscape and Urban Planning, vol. 177, pp. 303316, 2018.

[8] L. H. Guang, "'Xinhua Insight: Procedures unveiled for birth of Xiongan New Area," Xinhua News Agency, 2017, http://news .xinhuanet.com/english/2017-04/14/c_136206714.htm. 
[9] X. Hao, "The Millennium Project, the National Events, the Xiong'an New District, the historical legacy of our generation for future generations (千年大计国家大事雄 安新区我们这代人留给子孙后代的历史遗产)” (Chinese), China Economic Weekly, Beijing, China, 2017, http://kns.cnki.net/kns/brief/default_result.aspx.

[10] R. Okraszewska, A. Romanowska, M. Wołek, J. Oskarbski, K. Birr, and K. Jamroz, "Integration of a multilevel transport system model into sustainable urban mobility planning," Sustainability, vol. 10, no. 2, p. 479, 2018.

[11] B. J. Berry, “Urbanization, 2008," in Urban Ecology, pp. 25-48, Springer, New York, NY, USA, 2008.

[12] W. Lerner, "The future of urban mobility towards networked, multimodal cities of 2050," Global Future of Urban Mobility, 2009, https://robertoigarza.files.wordpress.com/2009/07/ rep-the-future-of-urban-mobility-2050-little-2011.pdf.

[13] B. van Wee and D. Ettema, "Travel behaviour and health: A conceptual model and research agenda," Journal of Transport \& Health, vol. 3, no. 3, pp. 240-248, 2016.

[14] A. Farooq, M. Xie, E. J. Williams, V. K. Gahlot, D. Yan, and Z. Yi, "Downsizing strategy for cars, Beijing for people not for cars: planning for people," Periodica Polytechnica Transportation Engineering, vol. 46, no. 1, p. 50, 2017.

[15] S. Melo, J. Macedo, and P. Baptista, "Guiding cities to pursue a smart mobility paradigm: An example from vehicle routing guidance and its traffic and operational effects," Research in Transportation Economics, vol. 65, pp. 24-33, 2017.

[16] F. Asim, M. Xie, S. Stoilova et al., "Transportation planning through GIS and multicriteria analysis: case study of Beijing and XiongAn," Journal of Advanced Transportation, vol. 2018, Article ID 2696037, 16 pages, 2018.

[17] Z. Rashedi, M. Mahmoud, S. Hasnine, and K. N. Habib, "On the factors affecting the choice of regional transit for commuting in Greater Toronto and Hamilton Area: Application of an advanced RP-SP choice model," Transportation Research Part A: Policy and Practice, vol. 105, pp. 1-13, 2017.

[18] Q. Luo, Y. Hou, W. Li, and X. Zhang, "Stop plan of express and local train for regional rail transit line," Journal of Advanced Transportation, vol. 2018, Article ID 3179321, 11 pages, 2018.

[19] L. Qin, H. Yufei, L. Wei, and Z. Xiongfei, "Express/local train plan optimization for urban rail transit in condition of fulllength and short-turn modes," IOP Conference Series: Materials Science and Engineering, vol. 383, article no. 012045, 2018.

[20] R. Palacin, Railway Passenger Satisfaction: How Good Is Good? Newcastle University, Newcastle upon Tyne, Tyne and Wear, UK, 2018, https://www.womblebonddickinson.com.

[21] R. Agarwal, "Public transportation and customer satisfaction: the case of Indian railways," Global Business Review, vol. 9, no. 2, pp. 257-272, 2008.

[22] E. Hassannayebi, S. H. Zegordi, M. R. Amin-Naseri, and M. Yaghini, "Train timetabling at rapid rail transit lines: a robust multi-objective stochastic programming approach," Operational Research, vol. 17, no. 2, pp. 435-477, 2017.

[23] Y.-C. Lai, M.-C. Shih, and G.-H. Chen, "Development of efficient stop planning optimization process for high-speed rail systems," Journal of Advanced Transportation, vol. 50, no. 8, pp. 1802-1819, 2016.

[24] Y. Zhou, Y. Bai, J. Li, B. Mao, and T. Li, "Integrated optimization on train control and timetable to minimize net energy consumption of metro lines," Journal of Advanced Transportation, vol. 2018, Article ID 7905820, 19 pages, 2018.
[25] Z. X. Miao, S. Q. Xin, D. Yong, S. R. Jia, and C. Yao, "Passenger choice behavior for regional rail transit under express/local operation with overtaking," Journal of Transportation Systems Engineering and Information Technology, 2016, http://www.tseit.org.cn/EN/abstract/abstract19297.shtml.

[26] M. Zhang, Y. Wang, S. Su, T. Tang, and B. Ning, "A short turning strategy for train scheduling optimization in an urban rail transit line: the case of Beijing subway line 4," Journal of Advanced Transportation, vol. 2018, Article ID 5367295, 19 pages, 2018.

[27] T. Cheng and M. Selden, "The origins and social consequences of China's Hukou system," The China Quarterly, vol. 139, pp. 644-668, 1994.

[28] K. W. Chan, "Post-Mao China: a two-class urban society in the making," International Journal of Urban and Regional Research, vol. 20, no. 1, pp. 134-150, 1996.

[29] Y. Zhao, "Leaving the countryside: rural-to-urban migration decisions in China," American Economic Review, vol. 89, no. 2, pp. 281-286, 1999.

[30] C. C. Fan, "Flexible work, flexible household: Labor migration and rural families in China," in Work and Organizationsin China Afterthirty Years of Transition, vol. 19 of Research in the Sociology of Work, pp. 377-408, Emerald Group Publishing Limited, 2009.

[31] M. Reisi, L. Aye, A. Rajabifard, and T. Ngo, "Land-use planning: Implications for transport sustainability," Land Use Policy, vol. 50, pp. 252-261, 2016.

[32] OECD, Compact City Policies (A Comparative Assessment), Organisation for Economic Cooperation and Development (OECD), 2012.

[33] F. Wefering, S. Rupprecht, S. Bührmann, S. Böhler, and B. Rupprecht, Developing and Implementing a Sustainable Urban Mobility Plan: Guidelines, European Commission, Brussels, Belgium, 2014, http://www.eltis.org/sites/default/files/guidelinesdeveloping-and-implementing-a-sump_final_web_jan2014b .pdf.

[34] D. Banister, "Cities, mobility and climate change," Journal of Transport Geography, vol. 19, no. 6, pp. 1538-1546, 2011.

[35] SAGPA, "Policies and governance for faster and more attractive rail transportation," Swedish Agency For Growth Policy Analysis (SAGPA), 2013, http://www.tillvaxtanalys.se/in-english/publications/pm/pm/2013-05-03-policies-and-governancefor-faster-and-more-attractive-rail-transportation--examplesfrom-china-india-and-japan.html.

[36] C. Chen, "Reshaping Chinese space-economy through highspeed trains: opportunities and challenges," Journal of Transport Geography, vol. 22, pp. 312-316, 2012.

[37] J. Campos and G. De Rus, "Some stylized facts about high-speed rail: a review of HSR experiences around the world," Transport Policy, vol. 16, no. 1, pp. 19-28, 2009.

[38] D. Albalate and G. Bel, "High-speed rail: lessons for policy makers from experiences abroad," Research Institute of Applied Economics, 2010, http://www.ub.edu/irea/working-papers/ 2010/201003.pdf.

[39] A. Ryder, "High speed rail," Journal of Transport Geography, vol. 22, no. 1, pp. 303-305, 2012.

[40] M. Janić, "A multidimensional examination of performances of HSR (High-Speed Rail) systems," Journal of Modern Transportation, vol. 24, no. 1, pp. 1-21, 2016.

[41] G. d. Rus and C. Nash, In What Circumstances Is Investment in High Speed Rail Worthwhile? The University of Leeds, 2007, http://eprints.whiterose.ac.uk/2559/. 
[42] M. Delaplace and F. Dobruszkes, "Thinking beyond the costbenefit analysis: the wider impact of high-speed rail on local development," Belgeo (Belgeo scientifique nationale de géographie en Belgique), 2016, https://journals.openedition.org/ belgeo/18166.

[43] Y. Yue, S. Wang, L. Zhou, L. Tong, and M. R. Saat, “Optimizing train stopping patterns and schedules for high-speed passenger rail corridors," Transportation Research Part C: Emerging Technologies, vol. 63, pp. 126-146, 2016.

[44] X. Xiao, L. Ling, J. Xiong, L. Zhou, and X. Jin, "Study on the safety of operating high-speed railway vehicles subjected to crosswinds," Journal of Zhejiang University SCIENCE A, vol. 15, no. 9, pp. 694-710, 2014.

[45] X. Jin, X. Xiao, L. Ling, L. Zhou, and J. Xiong, "Study on safety boundary for high-speed train running in severe environments," International Journal of Rail Transportation, vol. 1, no. 1-2, pp. 87-108, 2013.

[46] T.-Q. Tang, Y.-X. Shao, L. Chen, and H.-Y. Shang, "Modeling passengers' boarding behavior at the platform of high speed railway station," Journal of Advanced Transportation, vol. 2017, Article ID 4073583, 11 pages, 2017.

[47] X. Hu, S. Zhao, F. Shi, J. Huang, X. Shan, and W. Du, "Circuity analyses of HSR network and high-speed train paths in China," PLoS ONE, vol. 12, no. 9, p. e0176005, 2017.

[48] J. Zhang, "Analysis on line capacity usage for China high speed railway with optimization approach," Transportation Research Part A: Policy and Practice, vol. 77, pp. 336-349, 2015.

[49] O. Fröidh, "Market effects of regional high-speed trains on the Svealand line," Journal of Transport Geography, vol. 13, no. 4, pp. 352-361, 2005.

[50] I. Ajzen, "The theory of planned behavior," Organizational Behavior and Human Decision Processes, vol. 50, no. 2, pp. 179211, 1991.

[51] C. Hsiao and C. Yang, "Predicting the travel intention to take High Speed Rail among college students," Transportation Research Part F: Traffic Psychology and Behaviour, vol. 13, no. 4, pp. 277-287, 2010.

[52] B. Geng, H. Bao, and Y. Liang, "A study of the effect of a highspeed rail station on spatial variations in housing price based on the hedonic model," Habitat International, vol. 49, pp. 333-339, 2015.

[53] D. E. Andersson, O. F. Shyr, and J. Fu, "Does high-speed rail accessibility influence residential property prices? Hedonic estimates from southern Taiwan," Journal of Transport Geography, vol. 18, no. 1, pp. 166-174, 2010.

[54] H. Chen, D. Sun, Z. Zhu, and J. Zeng, "The impact of high-speed rail on residents' travel behavior and household mobility: a case study of the Beijing-Shanghai line, China," Sustainability, vol. 8, no. 11, p. 1187, 2016.

[55] L. Ye, "State-led metropolitan governance in China: Making integrated city regions," Cities, vol. 41, pp. 200-208, 2014.

[56] Y. Li, F. Wu, and I. Hay, "City-region integration policies and their incongruous outcomes: The case of Shantou-ChaozhouJieyang city-region in east Guangdong Province, China," Habitat International, vol. 46, pp. 214-222, 2015.

[57] J. Cao, X. C. Liu, Y. Wang, and Q. Li, "Accessibility impacts of China's high-speed rail network," Journal of Transport Geography, vol. 28, pp. 12-21, 2013.

[58] X. Fu, A. Zhang, and Z. Lei, "Will China's airline industry survive the entry of high-speed rail?" Research in Transportation Economics, vol. 35, no. 1, pp. 13-25, 2012.
[59] G. He, A. P. Mol, L. Zhang, and Y. Lu, "Environmental risks of high-speed railway in China: public participation, perception and trust," Environmental Development, vol. 14, pp. 37-52, 2015.

[60] M. Yin, L. Bertolini, and J. Duan, "The effects of the high-speed railway on urban development: International experience and potential implications for China," Progress in Planning, vol. 98, pp. 1-52, 2015.

[61] T. H. Roh, J. C. Lee, H. G. Kim, J. J. Kim, and Y. H. Jung, "Construction on decision support system for route location based on GIS," The International Archives of the Photogrammetry, Remote Sensing and Spatial Informa, 2008, http://www.isprs .org/proceedings/XXXVII/congress/2_pdf/4_WG-II-4/09.pdf.

[62] N. G. Ahmed and N. M. Asmael, "A GIS-assisted optimal urban route selection based on multi criteria approach," The Iraqi Journal for Mechanical And Material, pp. 556-567, 2009.

[63] B. Huang, "GIS-based route planning for hazardous material transportation," Journal of Environmental Informatics (JEI), vol. 8, no. 1, pp. 49-57, 2006.

[64] E. Ortega, I. Otero, and S. Mancebo, "TITIM GIS-tool: A GISbased decision support system for measuring the territorial impact of transport infrastructures," Expert Systems with Applications, vol. 41, no. 16, pp. 7641-7652, 2014.

[65] Y. Zhang, A. Li, and T. Fung, "Using GIS and multi-criteria decision analysis for conflict resolution in land use planning," Procedia Environmental Sciences, vol. 13, pp. 2264-2273, 2012.

[66] J. Brito, J. A. Moreno, and J. L. Verdegay, "Transport route planning models based on fuzzy approach," Iranian Journal of Fuzzy Systems, vol. 9, no. 1, pp. 141-158, 170, 2012.

[67] H. Kazan and C. Çiftci, "Transport path selection: multi-criteria comparison," International Journal of Operations and Logistics Management, vol. 2, no. 4, pp. 33-48, 2013.

[68] S. D. Stoilova, "An integrated approach for selection of intercity transport schemes on railway networks," PROMET TrafficeTransportation, vol. 30, no. 4, pp. 367-377, 2018.

[69] H. Deng and Z. Zhang, "GIS-based combination of fuzzy numbers and AHP method for selection of highway route: a case study from Anhui," in Proceedings of the 2010 International Conference on Mechanic Automation and Control Engineering, MACE2010, pp. 760-764, China, June 2010.

[70] P. Mongkut and N. Saengkhao, "Evaluation of alternatives in transportation planning using multi-stakeholders multiobjectives AHP modeling," in Proceedings of the Eastern Asia Society for Transportation Studies, vol. 4, 2003.

[71] M. S. Roodposhti, S. Rahimi, and M. J. Beglou, "PROMETHEE II and fuzzy AHP: An enhanced GIS-based landslide susceptibility mapping," Natural Hazards, vol. 73, no. 1, pp. 77-95, 2014.

[72] H. A. Hariz, C. Ç. Dönmez, and B. Sennaroglu, "Siting of a central healthcare waste incinerator using GIS-based multicriteria decision analysis," Journal of Cleaner Production, vol. 166, pp. 1031-1042, 2017.

[73] C. Çetinkaya, M. Kabak, M. Erbaş, and E. Özceylan, "Evaluation of ecotourism sites: a GIS-based multi-criteria decision analysis," Kybernetes, vol. 47, no. 8, pp. 1664-1686, 2018.

[74] A. Deluka, B. Karleua, N. Dragicevic, B. Karleuša, and N. Dragičević, "Review of multicriteria-analysis methods application in decision making about transport infrastructure," Gradevinar, vol. 65, no. 7, pp. 619-631, 2013, http://www.casopisgradjevinar.hr/assets/Uploads/JCE65201372850EN3.pdf.

[75] S. Kukadapwar and D. Parbat, "Estimation of optimal path on urban road networks using ahp algorithm," International Journal of Traffic and Transportation Engineering, vol. 6, no. 1, pp. 13-24, 2016. 
[76] Y. Meng, J. Malczewski, and S. Boroushaki, "A GIS-based multicriteria decision analysis approach for mapping accessibility patterns of housing development sites: a case study in Canmore, Alberta," Journal of Geographic Information System, vol. 03, no. 01, pp. 50-61, 2011.

[77] ERDAS, ERDAS Imagine. Hexagon Geospatial, Peachtree Corners Circle Norcross, ERDAS Imagine, 2014.

[78] ESRI, ArcGIS Desktop: Release 10, Environmental Systems Research Institute, Redlands, CA, USA, 2011.

[79] J. P. Brans and B. Mareschal, Multiple Criteria Decision Analysis: State of the Art Surveys, vol. 7, Springer, 2005.

[80] TWBG, "Cost of high speed rail in china one third lower than in other countries," the world bank group (TWBG), 2014, http://www.worldbank.org/en/news/press-release/2014/07/10/ cost-of-high-speed-rail-in-china-one-third-lower-than-inother-countries.

[81] Worldbank, "High-speed railways in China : a look at construction costs (English)," The World Bank Group, 2014, http:// documents.worldbank.org/curated/en/695111468024545450/ High-speed-railways-in-China-a-look-at-construction-costs.

[82] Baidu, "How much power does the CRH380 high-speed train consume in a hundred kilometers) CRH380 高速列车百 公里耗电多少? , Baidu, 2017, https://zhidao.baidu.com/ question/513154407.html.

[83] P. Lukaszewicz and E. Andersson, Green Train Energy Consumption Estimations on High-Speed Rail Operations, Royal Institute of Technology Aeronautical and Vehicle Engineering, Stockholm, Sweden, 2009.

[84] TCG, "Beijing - Tianjin intercity high speed train," in Travel China Guide (TCG), 2008.

[85] T. L. Saaty, "How to make a decision: the analytic hierarchy process," European Journal of Operational Research, vol. 48, no. 1, pp. 9-26, 1990.

[86] S. AHP, The Analytic Hierarchy Process: Planning, Priority Setting, Resource Allocation (Decision Making Series), vol. 2, McGraw-Hill, 1980.

[87] H. Wen and S. Lin, "Performance evaluation of highway passenger transport enterprises' operation based on the model of AHP-DEA. Industrial engineering and engineering management," in Proceedings of the IEEE 18th International Conference, pp. 12-14, Wuhan, China, 2011.

[88] C. Macharis, J. Springael, K. De Brucker, and A. Verbeke, "PROMETHEE and AHP: the design of operational synergies in multicriteria analysis. Strengthening PROMETHEE with ideas of AHP," European Journal of Operational Research, vol. 153, no. 2, pp. 307-317, 2004. 


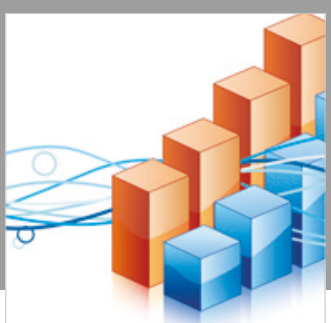

Advances in

Operations Research

\section{-n-m}
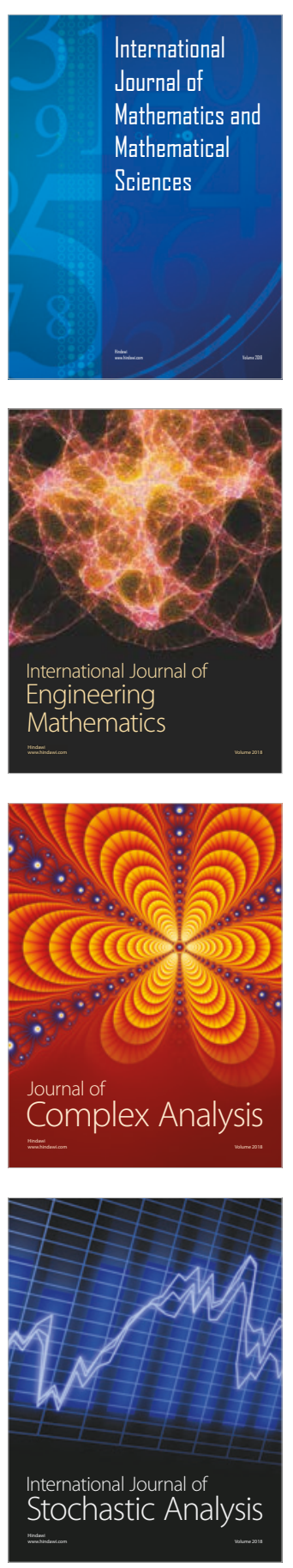
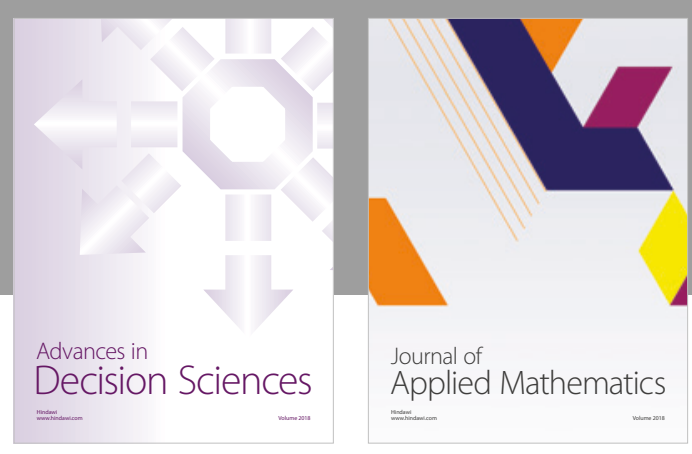

Journal of

Applied Mathematics
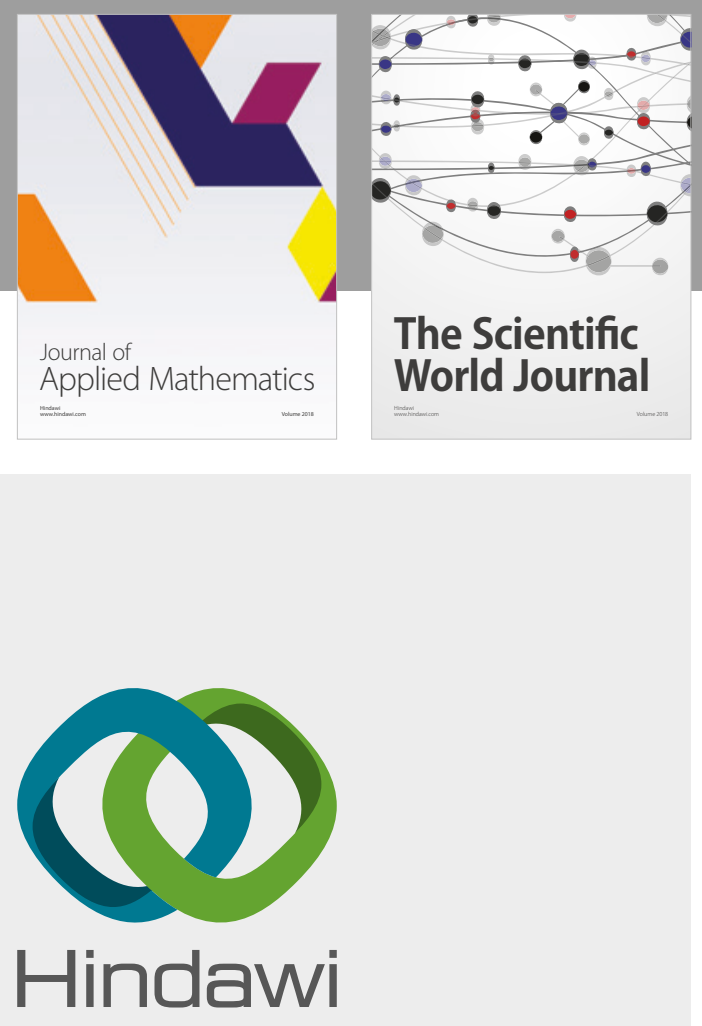

Submit your manuscripts at

www.hindawi.com

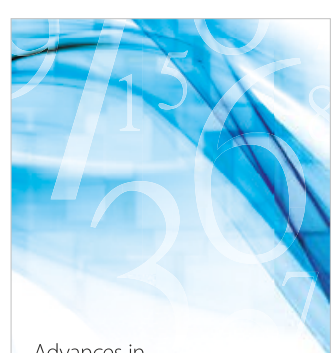

Advances in
Numerical Analysis
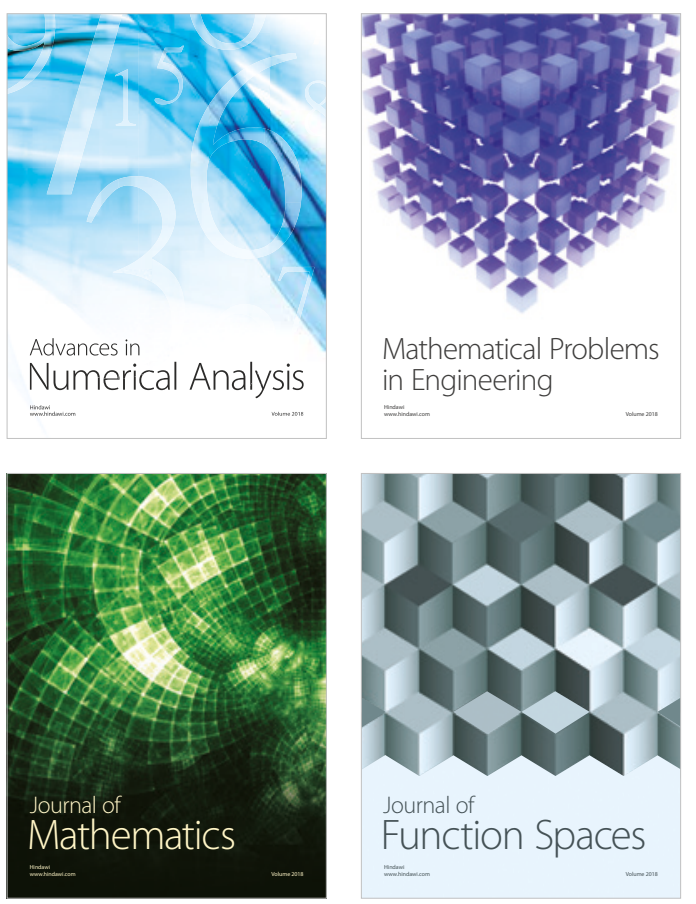

Mathematical Problems in Engineering

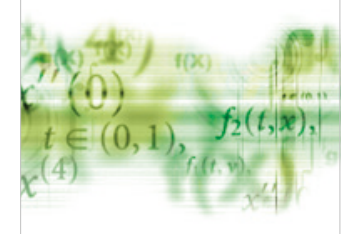

International Journal of

Differential Equations

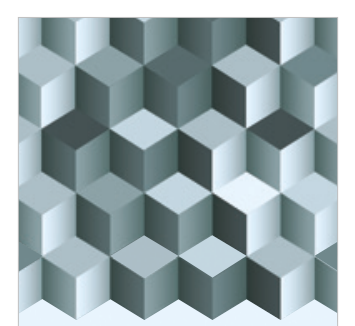

Journal of

Function Spaces

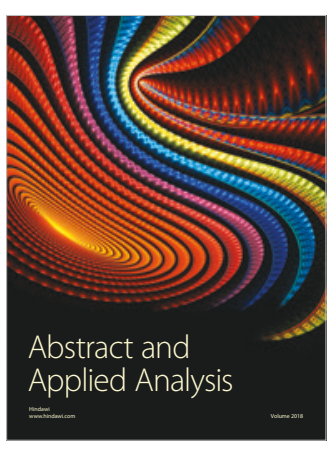

The Scientific

World Journal

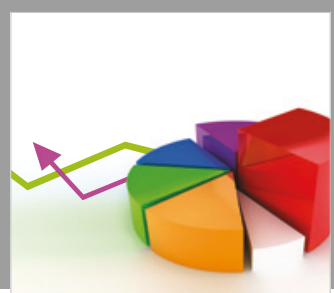

Journal of

Probability and Statistics
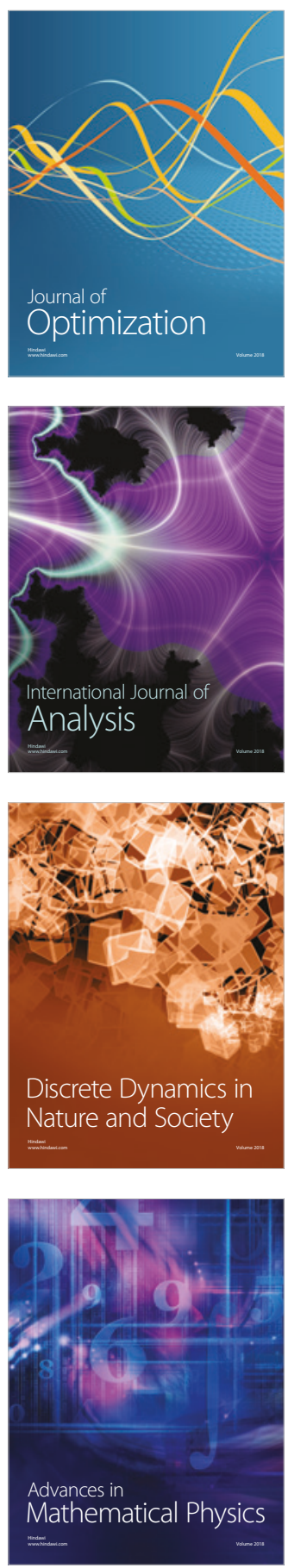